Cornell Law Library

Scholarship@Cornell Law: A Digital Repository

Cornell Law Faculty Publications

Faculty Scholarship

$1-1-2009$

\title{
Human Persons, Human Rights, and the Distributive Structure of Global Justice
}

Robert C. Hockett

Cornell_Law School, rch37@cornell.edu

Follow this and additional works at: http://scholarship.law.cornell.edu/facpub

Part of the Human Rights Law Commons, Law and Economics Commons, Law and Society Commons, and the Legal History, Theory and Process Commons

\section{Recommended Citation}

Hockett, Robert C., "Human Persons, Human Rights, and the Distributive Structure of Global Justice" (2009). Cornell Law Faculty Publications. Paper 46.

http://scholarship.law.cornell.edu/facpub/46

This Article is brought to you for free and open access by the Faculty Scholarship at Scholarship@Cornell Law: A Digital Repository. It has been accepted for inclusion in Cornell Law Faculty Publications by an authorized administrator of Scholarship@Cornell Law: A Digital Repository. For more information, please contact jmp8@cornell.edu. 


\title{
HUMAN PERSONS, HUMAN RIGHTS, AND THE DISTRIBUTIVE STRUCTURE OF GLOBAL JUSTICE
}

\author{
Robert Hockett*
}

\begin{abstract}
It is common for economically oriented transnational legal theorists to think and communicate mainly in maximizing terms. It is less common for them to notice that each time we speak explicitly of maximizing one thing, we speak implicitly of distributing another thing and equalizing yet another thing. Moreover, we effectively define ourselves and our fellow humans by reference to that which we equalize. For it is in virtue of the latter that our global welfare formulations treat us as "counting" for purposes of globally aggregating and maximizing.

To analyze maximization language on the one hand, and equalization and identification language on the other, is to "take distribution seriously" in legal and policy analysis. It is to recognize that law and policy are as distributive and person-defining as they are aggregative. It is also to recognize that law and policy treat us as equals in some respects-those by which they identify and "count" us as politically relevant-and as non-equals in other respects. Explicitly attending to these "respects" brings transparency about the degrees to

* Associate Professor of Law, Cornell Law School. Many thanks to Matt Adler, Dick Arneson, Kaushik Basu, Brian Bix, Robin Boadway, Kevin Clermont, Mike Dorf, Dan Farber, Marc Fleurbaey, Robert Frank, Alon Harel, Aristides Hatzis, Dan Kahan, Daniel Markovits, Jerry Mashaw, Trevor Morrison, Eduardo Peñalver, Jeff Rachlinski, John Roemer, Larry Solum, Alexander Somek, and Brad Wendel. I would like to dedicate the Article to Marilyn Inge, whose struggle with cancer commenced and concluded while it was underway. You are much missed.
\end{abstract}


which our laws and policies identify, "count," and treat us as equals in the right respects.

This Article addresses how to take distribution seriously in transnational legal and policy analysis. It does so by two means, keyed to the principal ways in which distribution is typically implicated in legal and policy analysis: first, by careful attention to the internal structures of the global welfare functions favored by most economically oriented analysts; and second, by reference to what linguists call the "cognitive grammar" of non-formal distributive language, a structure that mirrors the structure of distribution itself. Both modes of analysis yield a workable method to test proposed maximization norms for their normative propriety, and an attractive distributive ethic that can serve as a normative touchstone for transnational legal and policy proposals.

\section{TABLE OF CONTENTS}

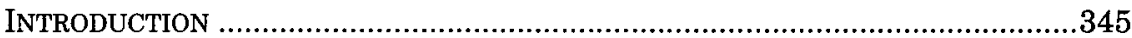

I. DISTRIBUTIVE CIRCUMSTANCES _........................................................354

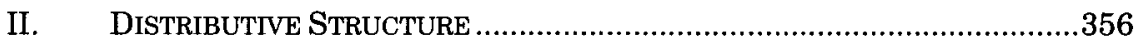

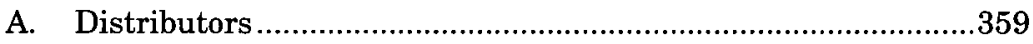

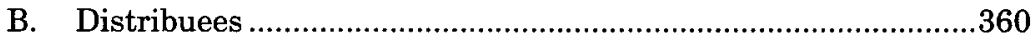

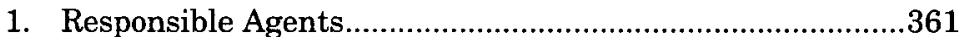

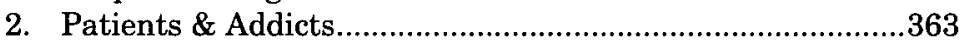

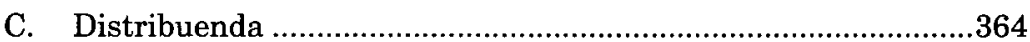

1. Welfare/Well-Being ...........................................................365

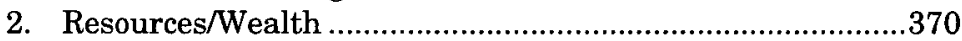

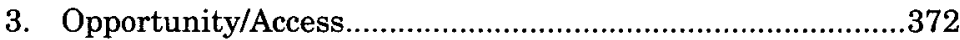

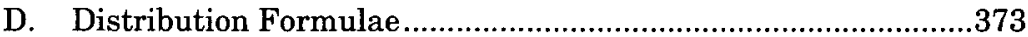

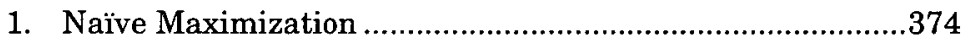

2. Prioritarian Maximining.....................................................381

3. Equalizing: Naive and Sophisticated Varieties.....................386

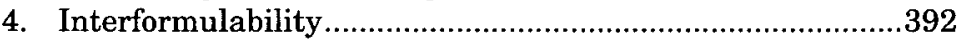

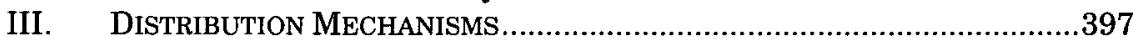

A. Mechanisms, Laws, Governments, Intergovernmental

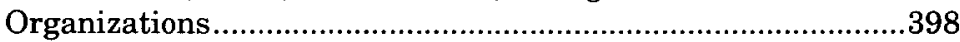

1. All Dressed Up and No Place to Go: Utilitarianism ..............399

2. More Tastefully Dressed, Still No Destination: Rawlsian Justice .400 
3. Locally Determinate, Globally Indeterminate

Prescription: Normative "Law \& Economics"......................401

B. One Satisfactory Mechanism...................................................404

1. One Fully Specifiable Mechanism: Real OpportunitySpreading.

2. Instantiability-Challenges and Ordered "Nth Bests"

3. The Role of Law

4. Comparative Legal \& Institutional Competencies

CONCLUSION 421

\section{INTRODUCTION}

Assume you are a globally oriented legal theorist, welfare economist, or policy analyst committed to some normative "master principle." You believe law and policy ought to concern themselves solely or mainly with "welfare," say, or with "well-being," "happiness," or some other such thing. As a result, you say we should "maximize" this thing. To that end, if you employ formal methods in conducting and communicating your analyses, you employ maximization formulae-most likely Bergson-Samuelson global welfare functions or some variant thereof. ${ }^{1}$

1. See Abram Bergson, A Reformulation of Certain Aspects of Welfare Economics, 52 Q.J. Econ. 310-34 (1938) (examining value judgments necessary for deriving conditions of maximum economic welfare); see also Kenneth J. Arrow, Social Choice and Individual Values (1951) (stating that economics reflects the making of different types of social choices among different people and societies); Paul Anthony Samuelson, Foundations of Economic Analysis (1947) (writing generally that meaningful theorems in diverse fields of economic affairs are derived from two basic hypotheses, one of which is that the condition of equilibrium is equivalent to the maximization of a certain magnitude). I provide formal characterizations of my own in Robert Hockett, The Impossibility of a Prescriptive Paretian (Cornell Law Sch. Leg. Studies Research Paper Series, Paper No. 06-027, 2008), available at http://ssrn.com/abstract=930460. The apparatus of global welfare functions is illuminatingly adapted to legal and global policy analysis in Matthew Adler, Well-Being, Inequality, and Time: The Time Slice Problem and Its Policy Implications (Pub. Law \& Legal Theory, Univ. Penn. Law Sch., Paper No. 07-30, 2007), available at http://ssrn.com/abstract=1006871. Also illuminating, if ultimately insupportable, is Louis Kaplow \& Steven Shavell, Fairness versus Welfare (2002) (arguing that social decisions should be made based on their expected effects on welfare, and not on notions of fairness, justice, and the like). The troubling nature of the book is visible from its face, with the title alone manifesting a rudimentary error in categorization: "Fairness" denotes a pattern of distribution, "welfare" an object of distribution that itself is 
It might have escaped your notice, but in doing these things, you do other things, too. Implicitly, you are thinking and advocating not only in terms of maximizing, but also in terms of distributing, and even equalizing. For in globally maximizing anything, we always are spreading one thing, and equalizing yet another. What is more, we effectively are defining ourselves and our fellow persons by reference to what we equalize. The attributes that "count" for purposes of global maximization are the attributes that make us legally relevant-and hence are the attributes to which we are reduced for legal and policy purposes.

For example, suppose you advocate that we globally maximize aggregate utility. In that case, you effectively are suggesting that we distribute things in a way that enhances that utility. You are also suggesting that those whose utility functions figure into your global welfare function be counted as equals in a particular respect-here, in respect of their utility functions. ${ }^{2}$ And the respect in which you count these individuals as equals is the identifying feature to which you assimilate or reduce them: If you are strictly utilitarian, individuals are their utility functions so far as your conception of global welfare is concerned. ${ }^{3}$ A person's utility function is the sole attribute in virtue of which she "counts" in your global welfare analysis. ${ }^{4}$

A concrete example: ${ }^{5}$ Say Beatrice and Benedict each have enough resources to subsist upon. Say further that "global society"

distributed fairly or unfairly. Foundational errors of precisely this sort are among those I hope to correct using the mode of analysis proposed in this Article. For more on objects and patterns of distribution see infra Parts II.C, II.D.

2. Some utilitarians use this fact to justify their position on putatively egalitarian grounds by claiming that everyone's utility function counts "for one" in the global welfare function. See infra note 15 and accompanying text.

3. This argument assumes each individual's utility function counts for "one" in the global welfare function. See infra note 14. It is also possible to weight different persons' utility functions differently-for example, counting the utility functions of the handicapped or desperately ill for more, as some "prioritarian" global welfare functions might do. In that case, the individual is globally identified by her weighted utility function; the objectionability of the identification will depend on the reasons for the differential weightings. For an expanded discussion, see infra Part II.D.

4. This statement assumes that yours is an unalloyed, "strict" welfare function. For in-depth analysis of "strict" and "mixed" functions, see infra Part II.D.

5. We can also render it more abstract and formal. A summary rendition of this kind is provided infra note 14 . 
has at its disposal an additional three units of what I will call "benefit stuff"-resources available to direct toward Beatrice and Benedict. ${ }^{6}$ Say finally that Benedict derives marginally more utility from benefit stuff than does Beatrice until he has received two units. ${ }^{7}$ Thereafter, Beatrice receives marginally more utility from benefit stuff than does Benedict. If we are utilitarians and, accordingly, wish to maximize feasible global utility under these circumstances, we will give the first two available units of benefit to Benedict, and the final available unit to Beatrice.

Call the benefits, prior to distribution, "generic benefit" units, or "benefits" for short. Call the benefits, after they are distributed, "aggregate-maximizing" units, or "maximizers" for short. ${ }^{8}$ Then there are three (even four) distinct ways to characterize what we have done. ${ }^{9}$ First, we could say we have maximized global utility. Second, we could say we have distributed benefits unequally ex ante, two to one in favor of Benedict. Third, we could say we have distributed maximizers equally ex post over Beatrice and Benedict, and (perhaps fourth) in that sense alone, we have treated Beatrice and Benedict as equals. In sum, we have distributed benefits unequally in a manner that treats Beatrice and Benedict as equals in respect of the utility functions with which we identify them-but in no other respect. ${ }^{10}$ In doing so, we have maximized something believed by utilitarians to exist: aggregate global utility. ${ }^{11}$

The reason to recognize the connection between maximization, distribution, equalization, and identification formulations is this: Maximization language and formulae tend to

6. You can think of it as money if you like, or as some other resource transformable into utility. See infra Part II.C.

7. I prescind here from worries about interpersonal comparability, as do utilitarians themselves. See infra Part II.C.

8. They are characterized accordingly, not just in terms of their ex ante material attributes, but in terms of their aggregate ex post utility effects when distributed over a given population of individuals. That is to say, these effects are "internal to" or "constitutive of" the things as thus individuated. Thank you to Matt Adler and Jeff Rachlinski for pushing me to make this point more clearly. I hope I have succeeded.

9. Three ways if we assimilate equalization into identification; four ways if we treat them as distinct characterizations.

10. The "in no other respect" qualifier proves important for reasons that emerge presently.

11. The existence in question often is contested, partly on measurability grounds. See infra Part II.C. I refrain from posing such objections here. 
lead us toward framing all of our thoughts in terms of maximization. ${ }^{12}$ And speaking exclusively in such terms leads us to thinking exclusively in those terms, as well. ${ }^{13}$ We are accordingly apt to lose sight of the fact that in maximizing we are also distributing, and that in distributing we likewise are equalizing some things while "disequalizing" other things over our fellow persons. Consequently, we are apt to overlook the fact that we are reducing our fellow persons to some single attribute of themselves-for example, their utility functions-by exclusively maximizing it. ${ }^{14}$

Our tendency to cast global legal and policy inquiries exclusively in maximizing terms is potentially problematic for a variety of reasons. First, it is as individuals-as recipients of distributions of various kinds-that our fellow persons engage our

12. They bear, to employ the increasingly popular idiom, "framing effects."

13. You likely know the word "maximandum" or its elliptical rendition, "maximand." Do you know the words "equalisandum" and "equalisand?" They can be found in the same dictionaries as their maximizing counterparts. See Robert Hockett, Why Paretians Can't Prescribe: Preferences, Principles, and Imperatives in Law and Economics, 19 Cornell J. L. \& Pub. Pol'y (forthcoming 2009) (working paper at 15-16), available at http://ssrn.com/abstract $=1266270$.

(stating that fair welfare is the appropriate form for legal prescription).

14. Here's a summary rendition of the point in formal terms: Maximization imperatives typically are expressed as injunctions to "Max" the global aggregate of social welfare, something called "W." This aggregate measure varies with the net "utility" or "benefits" experienced by individuals, which is called " $u$." $W$ is accordingly, in the typical case, said to be a "function" of individuals' summed $u$ measures. Hence $W=W(u 1, u 2, u 3, \ldots u m)$. The numeric subscripts index the $u$ functions of the $m$ individuals, and the imperative is to "Max $W=\sum u i$." Here, the Greek letter sigma indicates that we are summing, and the " $i$ " subscript indicates that we are to count each individual $i$ 's $u$-measure in the sum. This summing of course requires interpersonal comparability. See infra Part II.C.

Each individual's $u$-measure is typically viewed as a function of benefits and burdens received or experienced by, hence distributed to, the individual. For each individual $i, u i=u i(b 1, b 2, \ldots b n)$, meaning simply that the individual's $u$ measure is a function of a vector (or "basket") of $n$ distinct benefits and burdens. (A positive function of the benefits, and a negative function of the burdens. Comparative contributions and detractions made by distinct $b$ 's to the $u$-measure of course imply commensurability, hence something like "price ratios," among the $b$ 's. See infra Part II.C.) $W$ is accordingly, in the final analysis, a composite function $W \square u i \square b j$, or $W(u i(b j))$, meaning that $W$ is a function of aggregated $u$ measures, which are themselves functions of aggregated $b$-measures.

A quick formal way of putting the points made over the previous few pages, then, is that maximizing $W$ generally entails distributing $b$ 's to individuals $i$, who are "counted" and treated as equals for policy purposes solely by virtue of their $u$-functions. 
collective concern in the first place. Second, most of us wish to accord one another equal concern of some appropriate type-a type keyed to some politically appropriate conception of who or what we are-in our distributive legal and policy decisions. Talking and thinking exclusively in maximizing terms makes it harder to discern not only whether we are distributing, equalizing, and individuating ourselves by reference to the right things, but even whether we are maximizing the right things. ${ }^{15}$ The analytic linkage to which I am calling attention runs in both directions: We maximize the right things only when we distribute, equalize, and define one another by reference to the right things. ${ }^{16}$

15. Suppose, for example, we believe in equal opportunity to engage in the production of wealth. Then what we believe ought to be maximized is not just wealth, but wealth produced under conditions of equal opportunity. Call it "equalopportunity-grounded wealth." Call wealth not thus produced "opportunityindifferent wealth." Then to act as to maximize opportunity-indifferent wealth is to maximize the wrong maximandum, in light of our commitment to equal opportunity. It is best, then, to pay close attention to the linkages among all four phenomena-maximization, distribution, equalization, and identification. That way we enable ourselves to make use of the implications of competing proposed laws and policies upon all four as checks upon one another. This ensures that we are maximizing, distributing, equalizing, and identifying each other in respect of the right things.

16. To see this more graphically, imagine a simple variation on the story of Beatrice and Benedict considered above. Our society now aims to maximize aggregate forehead height rather than utility. Assume Benedict's forehead is higher than Beatrice's, that forehead height is genetically transmitted, and that transmission correlates in straightforward linear fashion with resource consumption. (That is, more resources improve the chances of genetic transmission. Please ignore for present purposes such complications as diminishing returns and any gendered determinants of forehead measures that there might be.) Now in the name of maximizing aggregate forehead height, we distribute all three available units of benefit stuff to Benedict. Maximization of global forehead height, equal treatment of individuals with respect solely to forehead heights, and disparate treatment of individuals in consequence of their equal treatment with respect to their forehead heights, then, come to the same here, just as before in the case of utility. The foreheadist might even offer the utilitarian's own favored pseudo-egalitarian rejoinder to your cry of eugenics. He says, "[B]ut we have counted each forehead only once!" See, e.g., John Harsanyi, Putatively Egalitarian Justification of Utilitarianism in Cardinal Welfare, Individualistic Ethics, and Interpersonal Comparisons of Utility, $63 \mathrm{~J}$. Pol. Econ. 309 , 320-21(1955) (arguing in favor of policies that maximize aggregate individual utilities, Harsanyi proposes giving an individual's utility an equal value of 1 , and maximizing the total unweighted sum or average).

Monstrous, you say. Agreed. But why? Surely it is because it is monstrous to identify a human being with her forehead height, which is precisely 
We would do well, then, to crack open our "maximizationspeak" and maximization formulae, in order to lay bare their inherently distributive, equalizing, and ultimately individualcharacterizing internal structures. Moreover, I will suggest, we would do well to do adopt a policy of addressing the maximization, distribution, equalization, and individual-characterization components of the inquiry in reverse order. ${ }^{17}$ It is critical to define ourselves, for legal and policy purposes, before we attempt to evaluate the forms of equalization, distribution and maximization wrought by our law and policy. ${ }^{18}$ But none of this is fully transparent until we

what the maximizing "global forehead function" does. But is an individual any more legitimately identified with her utility function than with her forehead? Are you any more responsible for your endorphin count-the innate neuro-chemical basis of your capacity to transform resources into utility-than you are for your forehead height? Is that what your fellow persons should reduce you to being? I think we will agree it is not. But this means we both disagree with utilitarianism, as here-and as typically-construed. Yet we are not apt to immediately see this when we think of the latter only in terms of what it maximizes, rather than also in terms of what it distributes, what it equalizes, and, therefore, what it take us for being. For who but the most churlish could be against "maximizing" something so vaguely benign-sounding as "aggregate utility," when distracted from fully considering what that means for each one of us as individuals and copersons?

We feel more immediately troubled by the forehead suggestion, I suspect, because we think immediately of foreheads as individuals' attributes, hence see immediately that "aggregate forehead maximization" is reducing persons to no more than their foreheads. ("Head-counts" with a vengeance.) "Utility," by contrast, tends more to strike us as a mysterious substance-widely spread "good stuff"- that none but curmudgeons could fail to want there to be more of. It is only upon reflecting that we see that this "utility" is produced physiologically and that "maximizing" it therefore requires channeling resources disproportionately to those with the utility-equivalent of high foreheads-steep utility curves-that we see the moral equivalence. Hence the importance of those forms of inter-translatability as between identification, equalization, and maximization that I wish here to emphasize.

17. Thank you to Trevor Morrison for suggesting that I emphasize this point.

18. Why? In short, because our principal care is with what we are and whether we are treated accordingly. Plausible answers to the question "in what respects we are properly regarded as equals" then proceed immediately from answers to the identification question. Plausible answers to the question "what ought to be distributed in what patterns and measures," in turn, proceed at once from our answers to the equalization question. And thereafter, in turn, the appropriate form of maximization takes care of itself: Distribute the right things 
open the internal structures of our maximization norms to systematic inspection.

To examine the internal structure of maximization language and maximization formulae is a way to "take distribution seriously"-if I may join others in using this now familiar locution. ${ }^{19}$

I thus propose in this Article to lay out with care what it might look like to take distribution seriously in normatively oriented transnational legal and policy analysis. ${ }^{20}$ I aim to specify in detail what I believe to be the conditions and the appropriately structured mode of analysis, respectively, under which normative global distributional assessment is called for and apt to bear fruit. The key is to focus on something that I have referred to a few times alreadywhat I call "distributive structure." That structure is manifest not only in all fully analyzed global welfare functions, as suggested above and as shown in more detail below, but also in the grammar of less formal distributive language itself. I shall accordingly be attending to both.

to the right people in the right measures, and you will have maximized that which it makes sense to maximize. This point is illustrated infra Part II.D.

Note also that many of those who seem most wedded to maximization formulae seem ironically, if nevertheless unwittingly, to be logically committed to precisely this claim. The so-called "individualist" global welfare functions they champion misunderstand that it is by reference to the individuals who constitute it that a society fares well. Where the articulation peters out for these people is at the point where we note that there are many different respects in virtue of which individuals can be individuated for legal and policy purposes, some of which are normatively arbitrary and others of which are not. See infra Part II.C. The term "individualism," as used in connection with global welfare functions, appears to originate with Samuelson, supra note 1.

19. See Ronald M. Dworkin, Taking Rights Seriously (1977). See also George A. Berman, Taking Subsidiarity Seriously: Federalism in the European Union and the United States, 94 Colum. L. Rev. 1 (1994); Michael Bratman, Taking Plans Seriously, 9 Soc. Theory \& Prac. 271 (1983); Richard Crasswell, Taking Information Seriously: Misrepresentation and Disclosure in Contract Law and Elsewhere, 92 Va. L. Rev. 565 (2006); Daniel Farber, Taking Slippage Seriously, 23 Harv. Env. L. Rev. 1 (1999); Jon D. Hanson \& Douglas A. Kysar, Taking Behavioralism Seriously: The Problem of Market Manipulation, 74 N.Y.U. L. Rev. 45 (2000). More waggish forays include William E. Forbath, Taking Lefts Seriously, 92 Yale L.J. 1041 (1983); Mark Kelman, Taking Takings Seriously: An Essay for Centrists, 74 Cal. L. Rev, 1829 (1986); and David A. J. Richards, Taking Rights Seriously, 52 N.Y.U. L. Rev. 1265 (1977).

20. And hence, among other things, what an ethically intelligible welfare or economic analysis of law might look like. See infra Part III. 
The remainder of the Article, then, proceeds as follows: Part I preliminarily characterizes the conditions that call for normative distributional assessment. These are the circumstances under which "who holds what" can and must be evaluated as "right," "wrong," "better," or "worse." Though these conditions are foundational and ought to be evident, their brief enumeration serves both to ground and clarify the more detailed discussion that follows.

Part II then systematically examines five classes of questions that arise when making most legal and policy decisions, be they global or local. These classes of question jointly constitute what I am calling "distributive structure." They also prove neatly tractable by reference to what linguists will recognize as the "cognitive grammar" of "to distribute" and cognate infinitives-verbs like "to allocate," "to apportion," "to mete out," etc. ${ }^{21}$ The gaps opened up by this grammar, deciding those who distribute, those to whom they distribute, what they distribute, per what pattern and by what means they distribute-afford a helpful starting point in discovering the full range of questions that distribution policy invariably implicates. And it is precisely this attention that I believe we must employ if we are to avoid "framing-blindspots" of the kind over which I have been raising red flags. ${ }^{22}$

It turns out that the selection of particular values to fill one or more variables discussed above tends to constrain ways in which we can fill the others. At least this is true of core values that we appear to share concerning what we are, what we most care about, what we are responsible for, what in consequence is fair, and thus what we implicitly acknowledge that we owe one another. ${ }^{23}$ Plausible

21. For an extensive discussion on this grammar, see infra Part II. It should not be surprising, upon reflection, that the structure of distribution would be mirrored in the language we use to communicate about it.

22. One might draw an analogy here to the general equilibrium analysis favored by more sophisticated economic theorists. The founding idea in both that case and this is that when items figuring into analysis are interdependent and in that sense constitute a system, the system itself is the appropriate unit of analysis. In the present case, the system in question is the set of variables carried by "to distribute" and cognate infinitives, all of which must be filled before a distributive claim can be determinate, and each of which must be filled in a manner compatible with the manners in which the others are filled.

23. Insofar as we think of the recipients of distributions as responsible agents, for example, it strikes us as more sensible to think of that which we ought to distribute as resources rather than utility, since responsible agents "produce" 
conceptions of appropriate distribution turn out to be rather like locations along an isoquant-a fair allocation "indifference curve," to put the point metaphorically. ${ }^{24}$

The discussion over Parts I and II accordingly converges upon what seems to be our logically entailed consensus understanding of the correct global allocation "isoquant." This is, in short, the distributional template, or the conception of global justice, grounded in our core value commitments, and systematized via the distributional theory, that structures our analysis. ${ }^{25}$ It is our vision for the way global distribution should proceed, given our broadly shared conception of ourselves as fundamentally equal rightsendowed, boundedly responsible forgers of good, well-faring lives out of scarce material opportunity.

their own utility out of the resources they are given. It is interlinkages of this sort that I have in mind here, and that I map throughout Part II.

Let me, while at it here, preemptively add that in employing the first person plural I make claims that are corroborated in two ways. First, I anticipate that the reader, on reflection, will agree that the value commitments to which I refer are indeed her own. Second, and perhaps more helpfully, in Part II I shall cite empirical evidence from the behavioral economics and sociological literatures indicating that these values are indeed widely shared, irrespective of partisan political identification. See, e.g., Norman Frohlich \& Joe A. Oppenheimer, Choosing Justice: An Experimental Approach to Ethical Theory (1993) (arguing that an empirical methodology should be applied to define universal concepts of fairness and distributive justice); John H. Kagel \& Alvin E. Roth, The Handbook of Experimental Economics (1995) (discussing the many experimental methodologies that can be used to evaluate decision making and values); Tom $R$. Tyler et al., Social Justice in a Diverse Society (1997) (explaining that concerns for social justice are robust across cultures).

24. An isoquant is simply a curve, different locations along which all take the same value in some formal inquiry. Probably the most familiar isoquants are the indifference curves endemic to microeconomic analysis. Changing $x$ coordinates along the same curve are said to be "compensated for" by changing $y$ coordinates, such that points corresponding to ordered pairs (interpreted, say, as "commodity bundles") are at home on the same curve and thus correspond to the same "utility" enjoyed by a consumer. If we think of normatively appropriate distributions of benefits and burdens as isoquant curves, we will see that here we are able to remain on the same "curve" by changing characterizations of what we distribute, for example, in response to changing characterizations of the pattern pursuant to which we distribute it. See infra Part II.D.

25. I refer to the upshot of Part II's grammatically-structured analysis as "meta-theoretic" because it involves explication of the structure of all complete theories of appropriate distribution-a structure that is manifest in the cognitive grammar of "to distribute" and cognate infinitives. 
Part III shows how readily the Part II-derived conception of appropriate distribution (hence identification, equalization, and maximization) lends itself to practical implementation, in light of our current legal and institutional environment. Indeed, this Part shows, the correct conception of appropriate distribution looks to be much more readily realizable than are its chief competitors, including welfare and wealth maximizing views, and "maximining" Rawlsian justice theory. Moreover, many of our legal principles prove best interpreted as aimed at vindicating the distributive ethic upon which the lines of Part II all converge. That bears obvious practical consequences for legal interpretation on the bench as well as for future law-making in the legislatures of the globe. It also bears critical theoretic consequences for those who debate the comparative merits of "law and economics," "welfarism," "Rawlsianism," and competing normative approaches to transnational law and legal theory.

Not surprisingly, then, I conclude the Article with some suggestions as to its implications for future transnational legal and policy analysis, based upon a distributive framework that makes normative sense.

\section{Distributive CIRCUMSTANCES}

Most things we find in the world are in some sense distributed, allocated, meted or spread out, etc. Not all such spreads lend themselves to intelligible normative critique. The chairs and the table in your kitchen are laid out in a certain arrangement. They are "distributed" over the floor in some geometrically specifiable pattern, and could be redistributed over that surface in many alternative ways. Absent some purpose or value in such arrangements, however, there is no reason to say it "should" be changed.

It also happens that many distributions of things do implicate values and purposes, some of them pressing or urgent. Such distributions accordingly fall subject to one or another mode of normative assessment. Insofar as you are sensitive to considerations of "feng shui" or geomancy, for example, even the spread of your furniture will lend itself to a form of normative evaluation. Some arrangements will aesthetically dominate others, such that you might incline toward redistributing your furniture until it accords with the "best" possible arrangement. Additional values may 
influence how one evaluates the arrangement-ease of reading in the late afternoon light, for example.

Domestic and international legal arrangements and public policies have the effect of distributing not simply tables and chairs over floors, but perceived goods and ills over persons. Evaluation accordingly strikes us as more pressing in these cases. Legal rules and rulings, statutory enactments, treaties, and government programs and policies of various sorts all tend to yield "winners" and "losers," the recipients of benefits and burdens.

Patterns of such policy-wrought wins and losses amount, relative to each status quo ante they displace, to redistributions of perceived goods and ills. These redistributions, like each arrangement they supplant, are subject to normative critique as readily as are furniture arrangements.

Less obvious to some legal and policy analysts, however, is that even when allocations wrought by legal rules and policies are neither foreseen nor intended, they remain ethically assessable: once brought to attention, they are subject to claims which allege such arrangements are "right," "wrong," "better," or "worse," and are therefore to be improved or deliberately left in place accordingly. In this light we are well advised to take at least summary stock of the circumstances under which distributive consequences can be said to be ethically better or worse. The set is small, but important. Fuller detail will build on the present foundations as we turn to the distributive-ethical assessment's full logical form in Part II.

First, there must of course be things that can be variably distributed, also known as "distribuenda." Second, there must be beings to whom these things can be distributed, or "distribuees." Third, those to whom the things can be distributed must hold preferences or interests in respect of their receiving or not receiving them. These items must be regarded or are properly regardable as beneficial or burdensome by their prospective recipients.

Fourth, the recipients of items, who hold preferences or interests in respect of the same, must hold legal or ethical claims to our regard. In other words, they must be entitled to our consideration of their preferences or interests as we distribute. And we must reciprocally consider the claimants' preferences or interests. It is this entitlement and its correlative obligation that render our assessment of distributions to the preferences of interest-holders normative, or ethical, in nature. 
This fourth condition is apt to create the most controversy, as it necessitates finding some distributive claims "ethnically cognizable," or deserving of a legal cause of action. And typically, the class of ethical claimants whom we consider entitled to our regard is smaller than the class of those who might literally claim. There are sentient creatures who presumably want things, or to be free of things, whom not everyone agrees deserve rights to have those wants considered. ${ }^{26}$ We will consider this matter more fully below, in II.B. For now it suffices simply to have marked the potential, and to have characterized the legally relevant distributive terrain.

Finally fifth, all items the distribution of which would be subject to ethical assessment must be "scarce." There must be potential for interests or preferences to diverge or conflict. With a finite number of benefits, distributions of all of them to a subclass of individuals will necessarily disadvantage the other classes. This prerequisite, combined with the previous one, entails a need for adjudication. We require both principled and practical means of balancing distribuees' potentially conflicting rights against one another.

\section{Distributive StRUCTURE}

Distribution is internally complex. It bears a structure, a logical form. Its form, unsurprisingly, is tracked by the form of the infinitives that name it. What linguists call the "case," "cognitive" or "valence" grammar of infinitives (like "to distribute") shows the structure to which distribution itself always conforms. ${ }^{27}$ The same

26. There are non-persons, for example, who seek some of what persons seek. Unborn fetuses might in some sense "prefer" to be permitted to reach full term. Among unambiguously non-human beings, in turn, bovines, pork, fish, and fowl presumably do not wish to be killed and eaten. At any rate, they often seek to avoid the violent prerequisites to their being eaten. See infra, Parts II.A, II.B.

27. Case, cognitive, or valence grammars divide sentences into predicate functions-typically verbs-and their argument places. Most of the latter are then filled by nouns and noun phrases, but in some cases they are filled by adverbs-predicates of predicates, hence second-order predicates. The number and kinds of arguments that a predicate can take constitute its "valency." See generally Charles J. Fillmore, The Case for Case, in Universals in Linguistic Theory 1-88 (Emmon Bach \& Robert T. Harms eds., 1968) (stating that the grammatical notion of case is a base component of the grammar of every language); Charles J. Fillmore, Toward a Modern Theory of Case, in Modern Studies in English 361-75 (David A. Reibel \& Sanford A. Schane eds., 1969) 
grammar accordingly should be attended to by normative distributional assessment if the latter is to be both complete and intelligible.

Call a claim concerning the rightness or wrongness, betterness or worseness of some law- or policy-wrought distribution a "distributive claim." For such a claim to be complete, hence determinate, it must fill all the gaps opened by the case grammar of "to distribute." The variables are, in effect, the pronouns and proadverbs that figure into the following questions: Who is being addressed by the distributive claim? What does the claim take for being distributed, or suppose ought to be distributed? To whom does it take that for being distributed, or suppose that it ought to be distributed? What pattern does the claim take properly to characterize permissible distributions to such recipients? And howby what physical means-does the claim take the distribution to be effectuable ? $^{28}$

(explaining that at the deep structure level, each sentence in a language consists of a verb and a collection of nouns in various cases); Studies in Linguistic Semantics (Charles J. Fillmore \& D. Terence Langendoen eds., 1971) (seeking to develop an adequate linguistic account of semantics). The analysis of predicates as argument-taking functions appears to have originated with Frege. See Gottlob Frege, Begriffsschrift, a formula language, modeled on that of arithmetic, for pure thought, in From Frege to Gödel: A Source Book in Mathematical Logic, 18791931 5-82 (Jan van Heijenoort ed., 1967) (proposing that "[a] judgment is obtained when the argument places between the parentheses attached to a functional letter have been properly filled["); Gottlob Frege, Function and Concept, in The Frege Reader 130-48 (Michael Beaney ed., 1997) (offering that "[t]he argument does not belong with a function, but goes with the function to make up a complete whole[").

28. In effect I supplement pure semantics-based case grammar here with argument-places additionally derived from linguistic pragmatics. For a claim actually to be made rather than simply entertained propositionally, it must be addressed to someone, and must take into account means by which addressees can effectively respond to it. In making this observation I am melding classical valence grammar with what Paul Grice would have called "conversational implicature." See, e.g., H. Paul Grice, Further Notes on Logic and Conversation, in 9 Syntax and Semantics: Pragmatics 113-27 (Peter Cole ed., 1978) (arguing that "implicatures" carry presuppositions that the listener must identify.); H. Paul Grice, Presupposition and Conversational Implicature, in Radical Pragmatics 183-98 (Peter Cole ed., 1981) (outlining "[a]n exposition of the thesis that the existential presuppositions seemingly carried by definite descriptions can be represented within a Russellian semantics, with the aid of a standard attachment of conversational implicature ["). 
The values with which "complete" claims fill these variables include the vocabulary discussed in Part I supra: distributors, distribuenda, distribuees, distribution formulae, and distribution mechanisms. The middle three variables must be filled for a distributive-ethical claim to be semantically complete-i.e., for the claim to bear determinate cognitive content in respect of whether a successfully individuated and characterized spread of goods or ills over persons is or would be right, wrong, better, or worse than some other conceivable spread. The first and last variables must be filled for the claim to be what might be called "pragmatically" completei.e., for the claim successfully to prescribe some possible course of action that might actually be taken. ${ }^{29}$

Opposing sides of overt or implicit distributive disputes, then, are effectively disagreeing over how one or more of the enumerated variables should be filled. The fact that such disputes are often implicit affords us one reason to bring the variables more explicitly into the foreground to clarify what, if anything, is really in dispute. But there is another reason for attending explicitly to the variables and, thereby, to the internal structure of distribution that they jointly constitute: it is that most of us by far, I believe, actually agree about how the variables ought to be filled when we assess them directly.

These claims can most effectively be shown, I believe, by elaborating and critiquing the leading variables that have been proposed. While some of these will look at least passingly familiar, they have not yet been considered together, in relation to each other at once. It is precisely this lack of systematic treatment, I believe, that renders the obscurity I lamented in the Introduction-confusion as to the relations among distribution, equalization, selfidentification, and maximization.

In an important sense, then, the argument that follows is cumulative: No one point will be fully appreciable until all points are made. But one has to start somewhere, and one can make piecemeal points at least provisionally appreciable. I will treat both the variables and candidates for filling them in sequence, doing my best to look ahead and/or backward to other variables while proceeding.

29. Semantic completeness is necessary, but does not suffice, to confer pragmatic completeness. 


\section{A. Distributors}

Domestic and transnational law and policy, we have observed, typically bear distributive consequences. That means that those who enact and then act upon law and policy effectively distribute benefits and burdens. In a derivative sense, those who evaluate law and policy distribute these same things as well. In the act of assessing or evaluating laws and policies bearing distributive consequences, one prescribes in respect of those consequences, and says, in effect, how she would distribute them. Another way of illustrating the point is to say that distribution, like "to distribute" and other infinitives that name it, always takes some singular or collective subject: There must be distributors-those who distribute, or who prescribe or determine how distribution ought to or is to proceed.

Who we understand the distributors to be will tend to play some role in determining our ethically distributive norms. The converse, of course, also holds: particular duties and those whom we take to be subject to such duties must categorically "fit" one another. Who, then, are they whom we take to owe each of us the benefit of acting in conformity with our distributive "ought" claims?

That question is probably the easiest that we will have to address in this Article. For there seems to be little disagreement over who the effective distributors are in most modern legal and policy settings, at least in modern democratic polities. "We"-the sovereign we, all who are addressed by legal and policy arguments over distributive propriety - are in effect taken to be the distributors.

We are "the people," the citizenry or humanity at large, who bear rights to take part in deciding what is distributively right. Or we are "the global or local policy community," the judges, legislators, advocates, diplomats, analysts, academics and others assumed to be thinking and acting on behalf of that broader constituency. The latter constituency, in such case, includes ourselves as its proxies or representative members. In either case, then, we are effectively distributing over ourselves so far as legal and policy debate is concerned. Interestingly, then, the class of distributors, particularly in modern polities, typically converges with that of distribuees-the next variable that we shall address.

Were we gods or, perhaps somewhat more humbly, elites looking over a polity in which rights were allotted unequally in our 
favor, there might be some wedge between "us" and the distribuees: We would be considering what "we" should distribute to "them," pursuant to what patterns and means..$^{30}$ This disparity between would-be distributors and would-be distribuees characterizes discourse about animal rights, for example. ${ }^{31}$ But the "we" and the "they" of most mainstream distributive discourse are one and the same in the sense that we are speaking of how we should apportion goods and ills among ourselves. How, then, should we characterize ourselves when considering what is to be distributed, and pursuant to what patterns and means?

\section{B. Distribuees}

Distribution, like "to distribute" and other infinitives that denote it, takes-or, "opens a grammatical space for"-not only subjects, but indirect objects as well. Where there are distributions, there are also distribuees, or those to whom things are distributed. Just as there must be "fit" between our distributive-ethical norms and how we characterize distributors, moreover, so must there be fit between those norms and how we characterize the distribuees whose rights those norms vindicate. How, then, do we or should we construe the recipients of distributed benefits and burdens? How should we characterize or identify them, and what should we take them to be?

The fact that we are distributors, and accordingly responsible for the distribution decisions ultimately made, says something important about us as distribuees. Curiously, however, not everyone seems to have caught the hint. Many legal and policy theorists and analysts, via positions they take as to how we should characterize distribuenda and distribution formulae as discussed below, effectively commit themselves to a view of distribuees that conflicts with the view that their likewise being distributors would seem to entail. It is tempting to hope we might end this conflict simply by

30. Some theorists view "analysts" as radically distinct from the citizenry at large. See, e.g., Kaplow \& Shavell, supra note 1, at 382-402.

31. See, e.g., Peter Singer, Animal Liberation 5-9 (1976) (discussing how humans ("we," the distributors) should distribute rights and considerations to animals ("them," the distribuees)). A not entirely dissimilar disparity as between distributors and distribuees is of course encountered in debate over the ethics of abortion, though in this case a critical feature of the dispute is precisely the issue of whether the distribuees are members of the distributor class. That is one reason why this dispute is more contentious than that over animal rights. 
bringing it to light. First, then, this Article will examine the gradually emerging consensus view of distribuees-the one on which most seem to agree when the question of how to construe them is posed directly. Then we shall turn to the view that is implicitly held, only when analysts fail to examine the assumptions underlying their proferred distribuenda and distribution formulae.

\section{Responsible Agents}

The gradually emergent consensus view of distribuees among those who concern themselves explicitly with the ethics of distribution is in harmony with their simultaneous role as the distributors. It is the view according to which distribuees are best considered what I shall call "boundedly responsible agents."

Boundedly responsible agents largely, though not completely, determine their own well-being. It is accordingly appropriate to hold them responsible, in some measure, for doing so. Not to do so is inconsistent with our according distribuees-and our according one another-appropriate respect as freely choosing, morally autonomous human beings. But boundedly responsible agents also are constrained, to a not fully determinable degree, in effecting their welfare by the environments into which they are born. That is what "boundedness" means in this context. Our inherited capacities, incapacities, advantages, and disadvantages-themselves features of our environments-permit us wide, and yet nevertheless limited, latitude in altering or exiting our environments.

This construal of ourselves coheres not only with our role as distributors, but also with our own experiences. We experience ourselves and others both as freely choosing and as also constrained to a vaguely determinable degree in the choosing. That experience is reflected in our capacities to experience guilt, shame, ambition for and frustration with self, resentment of and gratitude to others. It is also reflected in the "reactive attitudes" we often experience, attitudes which are intelligible only under conditions of relative freedom. ${ }^{33}$ The same appreciation of "boundedness," moreover,

32. I note infra Part II.B.2 that Dworkin and some others emphasize agents by emphasizing responsibility.

33. Notice of the link between responsibility and "reactive attitudes" bears a venerable pedigree. See Peter F. Strawson, Freedom \& Resentment, in Free Will 59-80 (Gary Watson ed., 1982) (illustrating that we must believe others have some control over themselves for us to have a genuine reaction to their behavior); 
underwrites our capacities to feel and extend mercy, forgiveness, sympathetic understanding, and charity toward self and toward others.

The construal of distribuees as boundedly responsible agents carries a cluster of interlinked consequences for normative distributional assessment: First, to the degree that we view distribuees as freely choosing, we find it appropriate to hold them responsible in part for what they choose, hence to live with the consequences of many of their choices. This is not merely a matter of punitive attitude, nor even of incentives-sensitive productive efficiency, though of course such considerations can sensibly underwrite the view. It is, more compellingly, a matter of human dignity and respect. It is part of what it is to view persons as agents-as practical forgers of fate-rather than the mere passive objects of fate, akin to children who "do not know any better" or "could not help it." 34

Second, an often ignored corollary of this form of respect is the imperative that all agents be viewed as equally dignified and equally deserving of most forms of respect. ${ }^{35}$ As observed in the Introduction, with a conception of who we are comes a conception of the features in virtue of which we are "morally" equal for legal and policy purposes. With the latter comes a conception of what ought to be distributed, and in what measure.

Another consequence that stems from the view of distribuees as boundedly responsible agents, then, is a commitment to conceptions of appropriate distribuenda, distribution formulae, and

see also Samuel Scheffler, Responsibility, Reactive Attitudes, and Liberalism in Philosophy and Politics, 21 Phil. \& Pub. Aff. 299, 299-323 (1992) (arguing that resistance to a diminished conception of responsibility fuels opposition to the liberal agenda).

34. It is tempting to suppose that some such commitment is what ultimately underwrites the Kantian idea of a "right to punishment." See, e.g., Randy E. Barnett \& John Hagel III, Assessing the Criminal: Restitution, Retribution and the Legal Process (1977), http://www.randybarnett.com/

assessing_the_criminal_.html (last visited Jan. 8, 2009) (explaining that the current criminal system overcomplicates the crime problem as it is unable to choose between conflicting goals and rationales to achieve swift, predictable, and just results); Patricia S. Greenspan, Responsible Psychopaths, http://www.

philosophy.umd.edu/Faculty/PGreenspan/Res/rp.html (last visited Jan. 8, 2009) (setting forth a philosophical view that separate ideas of freedom and responsibility would make better sense of psychopaths).

35. See, e.g., Robert Hockett, Why Paretians Can't Prescribe, supra note 13. 
distribution mechanisms that permit and give latitude to the operation of responsible agency. Appropriate distribuenda will be conceived as ex ante inputs to individual welfare or utility functions. The resulting "outputs," however, are in significant measure the responsibility of distribuees themselves. Appropriate distribution formulae, for their part, will speak to the ex ante distribution of inputs that operate independently of an individual's responsibility and initiative. The formulae will not be directly concerned with ex post, responsibility-dependent welfare outcomes. These will instead be treated as byproducts, mediated and influenced by distribuees' responsible agency. Preferred distribution mechanisms, in turn, will accordingly be those that give most effective expression to these ideals. We will see this borne out below.

\section{Patients \& Addicts}

The circumstances that bind individuals to certain situations can usefully be called "patienthood." ${ }^{36}$ To the degree that one really "cannot help himself," he is a patient, or an object of fate. He is acted upon rather than acting himself. Conversely, he is an addict- one who quite literally "cannot resist."

To the degree that our agency is bounded, we are all patients. But we are not generally apt to admit this. Indeed, we are apt to feel disgust or contempt, rooted perhaps in the perceived threat that is posed by role-models with whom we subconsciously but reluctantly identify. Owing to that fact, along with the indeterminacy of the boundary between choice and chance in the many borderline cases each of us experiences each day, we tend generally to let the boundary "take care of itself." We do so simply by trying as hard as

36. I intend "patient" as used here, like "agent" before, in its grammatical sense-as the recipient rather than the initiator of an action. See, e.g., Bernard Comrie, 2 Language Universals and Linguistic Typology: Syntax and Morphology 42-43, 58-61 (1989) (differentiating between the agent (giver) and patient (recipient)); John Lyons, An Introduction to Theoretical Linguistics 340, 350 (1967) (defining "patient" as the "goal," or recipient of an action, as opposed to the "agent" as an "actor"); see also Ronald Dworkin, Sovereign Virtue: The Theory and Practice of Equality 303 (2000) (referring to patients as "addicts," or ones that cannot resist); Daniel Markovits, How Much Redistribution Should There $B e$ ?, 112 Yale L.J. 2291, 2295 (2003) (explaining that one may view people as "agents, who act upon the world in ways for which they are responsible, and patients, on whom the world acts in ways they cannot control"). 
we can, then forgiving ourselves once we finally "let go" when we must.

Doubtless for reasons that are rooted in these ideals, as well as related concerns with incentives, ${ }^{37}$ few, if any, legal or policy analysts wittingly construe distribuees as patients. Instead, they effectively commit themselves to that construal. They do so via the positions they take in respect of appropriate distribuenda, distribution formulae, and distribution mechanisms-positions whose logical consequences are often unappreciated.

Because welfare or "utility" draws attention to outputs rather than inputs, for example, it is difficult to be unambiguously welfarist or utilitarian without effectively treating distribuees as not being responsible for outcomes, and hence as patients. ${ }^{38}$ Similarly, because resources and wealth are readily viewed as welfare inputs, advocates of ex post wealth distribution, even apart from the working of distribuees' responsible choices, likewise treat distribuees effectively as patients. ${ }^{39}$

Finally, insofar as any distribution mechanism fully manifests a distribution principle such as that just mentioned, it too treats distribuees as mere patients. ${ }^{40}$ Insofar as it fails to be egalitarian prior to or apart from the operation of distribuees' responsible choices, by the same token, it violates ethical equality and respect for agency. It does so by effectively treating some distribuees as deserving of less than others even before these individuals have opportunity to act to increase their material opportunity.

\section{Distribuenda}

Distribution and its infinitives take, in addition to the subjects and indirect objects that implicate distributors and

37. Those incentives and their consequences are traced infra. In brief, letting agents too readily "off the hook" results in the unjustifiable conscription of those who act responsibly by those who do not. It also, and equivalently, results in ethically cognizable inefficiency.

38. See infra, Parts II.C, II.D.

39. See infra, Parts II.C, II.D.

40. This prospect of course suggests that distribution mechanisms might be composite in nature: Market allocations followed by taxation and redistribution would constitute a familiar case in point. The suggestion is borne out infra Part III. 
distribuees, direct objects as well. There are always distribuenda, or distributed things.

There has generally been more overt dispute in the theoretical literature over appropriate distribuenda than over who or what the distributors and distribuees are. ${ }^{41}$ This is likely the product of what I detailed above-our failure thus far to think through the linkages among all of distribution's constitutive variables. One consequence is that alternative proposed distribuenda turn out to be ethical touchstones. They serve as flags under which other disputes-disputes over distribuees and distribution formulae in particular-are pursued.

\section{Welfare/Well-Being}

A particularly venerable family of proffered distribuenda have gone by such names as "utility," "welfare," "well-being," "happiness," "satisfaction" and cognate expressions. ${ }^{42}$ Although authors construe the terms differently, they all share distinct family resemblances rooted in one guiding idea. ${ }^{43}$ The latter runs thus: faring well is what matters to people. Indeed this is trivially so, in view of the meanings of words such as "good" and its adverbial form, "well," themselves. Terms such as "utility," "satisfaction," "happiness," and the like are often even defined simply as being whatever is effectively "produced" by people's preferences (or on some readings, their interests-"enlightened," "rational," "ideally informed," or otherwise) being satisfied. ${ }^{44}$ This line of thinking concludes that law and policy should aim at enhancing these magnitudes - to do so is simply to satisfy people.

41. See, e.g., Amartya Sen, Inequality Reexamined 12-15, 22-23 (1993) (discussing liberty and equality as prime examples, focusing on the debate over what to distribute rather than to whom); Dworkin, supra note 36, at 111-19; Gerald A. Cohen, Equality of What? On Welfare, Goods, and Capabilities, in The Quality of Life 23 (Martha Nussbaum \& Amartya Sen eds., 1993) (focusing on the distribution of goods and welfare themselves rather than their distributors).

42. See, e.g., Amartya Sen, Utilitarianism and Welfarism, 76 J. Phil. 463 (1979) (developing several models of proffered distribuenda, including utility and welfare theories). For an exhaustive discussion of the concepts of welfare and well-being, as well as of various conceptions of these, see James Griffin, WellBeing: Its Meaning, Measurement and Moral Importance (1986) (establishing strong links between well-being, utility, and fulfillment of strong desires).

43. See Sen, supra note 42; see also Griffin, supra note 42.

44. See Sen, supra note 42 ; see also Griffin, supra note 42. 
Note that nothing as yet is implied here as to what such "enhancing" or "satisfying" would look like. Things remain pitched at a high level of abstraction. One might then wonder why anyone would propose anything other than welfare as distribuendum. I think what is objected to is not welfare as an abstract normative distributional touchstone. Rather, what people protest is either: (a) "welfare" as construed, by some of its more eccentric or irresponsible advocates; relatedly (b) welfare as mere output that is aggregated and globally "maximized," without regard to the way in which it is produced; or (c) welfare as literal, direct distribuendum. ${ }^{45}$

Construal-based objections take various forms. Most are prompted by unduly narrow or bizarrely overbroad stipulations by advocates as to what should count as well-faring. ${ }^{46}$ Some early utilitarians, including Bentham and Edgeworth, sometimes suggested that all that should "count" as well- or ill-faring was hedonic experience. ${ }^{47}$ Bentham named his rendition of this commitment the "Pleasure Principle." Edgeworth, for his part, predicted that one day a "hedonimeter" would be developed, with which we would measure utility as readily as temperature. ${ }^{48}$ Ramsey and von Neumann made similar suggestions. ${ }^{49}$ It is even now often suggested that utility and disutility are reducible to endorphins and C-fiber counts, respectively, as "water" has come to be specified with definitive precision as $\mathrm{H}_{2} \mathrm{O} .^{50}$

Suggestions like these prompt predictable objections and equally predictable responsive refinements. Best known among the latter are those of such thinkers as Mill, Sidgwick, and Griffin. These

45. This is an objection of my own. One cannot directly distribute welfare, but must distribute something else that is thought to yield welfare.

46. See Jeremy Bentham, An Introduction to the Principles of Morals and Legislation (1823) (noting that pain and pleasure govern mankind, and that utility, expressed broadly, is an object that produces happiness or pleasure); Francis Ysidro Edgeworth, Mathematical Psychics: An Essay on the Application of Mathematics (1881) (establishing analogies between principles of utility and happiness with principles of physics and mathematics devoted to maximum energy theory).

47. See Bentham, supra note 46; Edgeworth, supra note 46.

48. Edgeworth, supra note 46, at 101.

49. See, e.g., John von Neumann \& Oscar Morgenstern, The Theory of Games and Economic Behavior (1947).

50. See, e.g., John E. Roemer, Egalitarian Perspectives 117 (1994) (explaining that in certain environments, differences between the utility of two actors may be reducible to a difference in their endorphin levels). 
thinkers have sought to take seriously the prospect that a well-faring human life might be something more than an extended orgasm or itch-scratching. ${ }^{51}$ They nevertheless tend to treat the refined form of welfare as a mysterious sort of substance, the aggregate quantum of which ought to be maximized, at least until their conceptions grow so refined as no longer to lend themselves to scalar aggregation. ${ }^{52}$

Latterday exponents of the earlier Benthamite crudity do not banish all welfare that is not "hedonic" in nature. They push instead to the other extreme, counting as ethically cognizable "welfare" the satisfaction of any preference whatsoever. ${ }^{53}$ And so, they have occasioned predictable objections, as well as refinements reminiscent of those put forth by Griffin. ${ }^{54}$ Objections in this case take account of the fact that a preference can itself be ethically problematic, either in its own terms-because, say, it is a preference to be unethical-or as the product of, hence as endogenous to, antecedent distributive circumstances that are themselves ethically objectionable. ${ }^{55}$

51. See, e.g., Griffin, supra note 42. Griffin's refinements have turned out to be so extensive that he has ultimately found himself compelled to abandon consequentialist ethics altogether. See James Griffin, The Human Good and the Ambitions of Consequentialism, 9 Soc. Phil. \& Pol'y 18 (1992).

52. That is, at least until they view the determinants of welfare as being too complex to be reduced to a single metric. See Griffin, The Human Good, supra note 51 .

53. See, e.g., Kaplow \& Shavell, supra note 1, at 421-22 (noting that "[t]he idea of an analyst substituting his or her own conception of what individuals should value for the actual views of the individuals themselves conflicts with individuals' basic autonomy and freedom["). The short answer is that imprisonment, too, "conflicts" with basic autonomy and freedom-that of convicts. Few, if any, disapprove of autonomy and freedom, just as few disapprove of welfare or well-being. But the question has always been how we are to demarcate individuals' legitimate spheres of autonomy satisfactorily, and that question of satisfactory demarcation is part of the question of fair allocation. See infra Part II.D. The "we do not want to judge" disclaimer accordingly avails nothing. Determining fair allocation is judging period. All law and policy require such determinations. Use of the ethically loaded terms "welfare" or "well-being" rather than less deck-stacking terms such as "preference-satisfaction," moreover, registers precisely such judgment.

54. See Griffin, The Human Good, supra note 51, at 14.

55. For more information on the preference to be unethical (or those preferences that will not be maximized under any social welfare system), see Robert Hockett, Reflective Intensions: Two Foundational Decision-Points in Mathematics, Law, and Economics, 29 Cardozo L. Rev. 1967, 2094 (2008) (arguing that general jurisprudence and welfare economic theory can be illuminated by "intentional" or "criterial" choice and "self-reference," which are 
It is deeply incoherent, for example, to say of the thief that "he fares well," or that "his well-being improves," when he succeeds in stealing more goods. ${ }^{56}$ For the thief is by definition the person who violates distributive norms in conformity to which "good" and "well" must themselves be defined. ${ }^{57}$ To call the thief's satisfaction "welfare" rather than "satisfaction" is to conflate desire with desert. It is therefore to lose the distinction between description and prescription, positive and normative, "is" and "ought." It is accordingly to relinquish the capacity to prescribe or evaluate at all, hence to abandon normative legal or policy analysis itself. ${ }^{58}$

It would seem likewise, if less starkly misleading, to say of the slave who has come to accept what she's told of her putative racerooted "inferiority," that she is "better off," or that "her welfare improves," relative to some alternative circumstance in which she rejects her race-rooted identification and demands respect. ${ }^{59}$ It can be conceded that because, unlike the thief, she is presumed faultless, we are able to view her having come to terms with her situation as affording some good in mitigating her otherwise bad lot. But to say that her "welfare" is improved in this way is nevertheless misleading for its failure to register the wrongfulness of the circumstance that renders her resignation consoling. If we are to maintain the distinction between positive and normative with precision, then, it is

mathematical theoretical concepts that clarify our assumptions and possible solutions to problems of freedom and just distribution). For more on preferences that are endogenous to unfair antecedent distributive circumstances, see, e.g., Amartya Sen, Equality of What?, in Equal Freedom: Selected Tanner Lectures on Human Values 307-30 (Stephen Darwall ed., 1995) (rejecting utilitarian equality, total utility equality, and Rawlsian equality to argue instead for "basic capability equality," a theory of equality that prioritizes a person's ability to do certain basic things); Gerald A. Cohen, On the Currency of Egalitarian Justice, 99 Ethics 906, 922-23 (1989) (exploring a range of views on egalitarianism and values that compete with distributive equality, arguing for a wider, access-oriented egalitarianism).

56. Or that Nazis are "better off" when they murder more "non-Aryans," etc.

57. See Hockett, Prescriptive Paretian, supra note 1; see also Hockett, Why Paretians Can't Prescribe, supra note 13.

58. See Hockett, Prescriptive Paretian, supra note 1; see also Hockett, Why Paretians Can't Prescribe, supra note 13.

59. Even if the respect is not forthcoming. But see Arthur Schopenhauer, Die Welt als Wille und Vorstellung (1844) (recommending, in Vol. I, Bk. 4, Vedantic resignation). 
again more accurate in these "tamed housewife" cases ${ }^{60}$ to say "she's resigned to her unjust circumstances" than that "her welfare is higher."

Additional objections to welfare as distribuendum are rooted in the fact that welfare is not a directly measurable or distributable substance. $^{61}$ The physical distribution problem is the most immediately apparent. Whether understood as endorphins, preference-satisfactions, idealized satisfactions, etc., welfare is simply not something directly doled out. It is, rather, at best "produced" by distribuees, from physical things that are doled out. That opens two lines of concern flagged by theorists who do not consider themselves unalloyed welfarists.

First, in order practically to be welfarist, one must operationally be "something elseist" as well-e.g., wealthist, resourcist, etc. ${ }^{62}$ Second, since welfare emerges from what distribuees do with whatever is literally distributed, and since the latter materials are in most cases scarce, would-be distributors must decide how to respond to distribuees' capacities and responsibilities for producing their own welfare out of what they are allotted. I will discuss the fuller significance of these opened lines below, both in connection with competing proposed distribuenda, and in connection with distribution formulae.

There are, finally, familiar measurability concerns occasioned by welfare as proposed distribuendum. On most present-day construals, as noted above in II.C.1, welfare no more lends itself to practicable quantifiability or interpersonal comparability in the holding than it does to direct distributability. Commensurability is the one measurement task for which welfare does not present difficulties, since in theory it serves as a numéraire in terms of which more concrete items are comparatively valued. The trouble, of course, is that in view of its unamenability to actual quantification or interpersonal comparison, it can serve as numéraire only "in theory." It is of no practical use at all.

We shall presently see that "subjective" welfare is the inverse image of more "objective," physical distribuenda and can be

60. The "tamed housewife" is featured in Amartya Sen, The Standard of Living 11 (1987).

61. See supra note 45 and accompanying text.

62. More on wealth, resources, etc., infra Part II.C.3. 
measured as such. In fact it appears that the two things-welfare and the physical items from which distribuees derive it-must be brought together in some way for distribuendum-measurement problems to be addressed in an ethically intelligible manner. This, along with its practical consequences, will emerge in my discussions below.

\section{Resources/Wealth}

The principal competitors to welfare as proposed distribuendum have historically been material resources or wealth of one sort or another. "Resources," like "welfare," have been defined in terms ranging from the simple and abstract, to the complex and concretely particular. The simplest and most abstract characterization is simply as wealth, or an index-tied medium of exchange or scalar "stuff" that recipients can transform into welfare purchasing and consuming more variegated goods and services. ${ }^{63}$ More complex and concretely particularized characterizations include Rawlsian "primary goods," among others. ${ }^{64}$

As indicated at the end of the previous subsection, the advantages and disadvantages of resources as prospective distribuenda can be viewed as the inverse image of the disadvantages and advantages of welfare. First, resources are directly distributable. Second, they are readily measurable, at least with respect to simple quantification and interpersonal comparability in the holding, as noted above in II.B.1. And finally third, they take into consideration the possibility that distribuees will affect their own well-being. Considering resources as distribuenda then assumes

63. This includes risk-bearing services, the fuller significance of which emerges infra Part III.B.2. This rough characterization of wealth, incidentally, is cognate with but not identical to that offered by Posner in the 1980s, as discussed infra Part III.A. A suitable synonym for my usage would be "purchasing power."

64. See, e.g., John Rawls, A Theory of Justice 54-55, 78-81, 358-65 (rev'd ed., 1999) (defining "primary goods" as things that every rational man is presumed to want); see also John Rawls, The Law of Peoples (2000) (reformulating the definition of "primary goods" more abstractly as those goods necessary for a system to maintain its "distinctive structure" and to achieve its "purpose and role"). I prescind from those complexities here. They are not germane to present purposes and bracketing them accordingly does no harm. A more complete discussion is found in Robert Hockett \& Mathias Risse, Primary Goods Revisited, Cornell J. Econ. \& Phil. (forthcoming 2009) (on file with author), available at http://ssm.com/abstract $=931048$. 
that the satisfactions distribuees enjoy will ride partly upon what they $d o$ with their resource allotments. That seems to most people both ethically right and efficient in the sense of providing incentives to individuals to assume responsibility for their own well-being. We will resume this discussion when we turn to distribuees, distribution formulae and distribution mechanisms below.

Resources' disadvantages are straightforward functions of the degree to which, if any, considerations of the propriety of their spread are detached from objective considerations of welfare. Where that detaching is complete and entire, resourcism devolves into fetishism. We should always bear in mind the fact that resources are, trivially, in every case resources for something. They count as resources, as distinguished from merely insipid, ethically inert substances, only by reference to the purposes and preferences that users have for them. "Wealth" for its part-derived as it is from the Middle English "weal," as in "common weal"-is cognate with "well-being" itself. ${ }^{65}$ So resources or wealth even to count as such, must be tied in some manner to that which concerns the distribuees who engage our normative distributional concern, or well-being. The question thus opened is: in what way, precisely? The full answer emerges only once we have arrived at proposed distribution formulae and distribution mechanisms. ${ }^{66}$

Relations between resource and welfare implicate measurement matters, too. As noted before, resources raise no direct challenge where quantification and comparison of interpersonal holdings alone are concerned. But they do raise an indirect challenge where the ethical relevance of quantities and holdings are concerned. For ethical relevance here, as just observed, is tied partly-though critically-to welfare-yield. The indirect challenge is this: Suppose that a given distribuendum yields differing welfare measures to differing distribuees. Suppose also that welfare is ultimately what matters. Suppose finally that welfare itself is, as observed earlier, not practicably quantifiable or interpersonally comparable in the holding. If we accept those three plausible suppositions, then it is not immediately apparent what ethically cognizable advantage is offered by resources' ability to be quantified.

65. See Hockett, Why Paretians Can't Prescribe, supra note 13.

66. See infra Parts II.D, III.A. 
The direct challenge is this: Suppose resources are disparate. Suppose also that each is not properly subject to its own distribution formula. Some means of indexing, then, must be developed for such terms as "total resources" or "wealth" to bear content. But now note that de facto valuation occurs when comparative weightings are assigned to vector components in fashioning the scalar along which "total resources" or "wealth" are to be quantified. Note also that ethically satisfying such valuation must again involve measurementchallenging welfare. It follows, in such case, that indexing too will be problematic. How, then, to make resource measurement ethically intelligible?

Fortunately, it happens that a well specified distribution mechanism allows both for unobjectionable indexing and coupling of measurable resources and the more abstract notion of human welfare. I must then again ask the reader to bear with me until we have completed this Part.

\section{Opportunity/Access}

The difficulty in considering resources as distribuenda actually mirrors the characterization of welfare as such. The danger that afflicts welfare is that all preferences, even admittedly antiethical ones, might be counted as affording normatively valuable "welfare." The danger that afflicts resources is at the other extreme. It is that no preferences will be considered when labeling ethically inert, non-valued substances "resources." ${ }^{.67}$ The idea is that because welfare, or "advantage," is what matters to people, material "stuff" in itself is not ethically salient. Moreover, since material resources are varied and thus in need of commensuration if they are to be spread under one distribution formula, some common denominator is required. Again that may be termed as "welfare," or "advantage." Accordingly, the item whose spread can intelligibly engage our distributive-ethical concern or assessment, even if material in nature, must be understood as "opportunity for welfare," or "access to advantage." For it is only in virtue of their connection to human well-

67. It is worth noting that "resource" is subject to objectionable overinclusive construal as well, just as "welfare" is subject to objectionable underinclusive construal: Just as it is philistine to treat welfare as solely hedonic, it is grotesque to claim all things the possession of which might afford pleasure can be counted as "resources." Slaveholders and some husbands seem often to have viewed human beings in this way, for example. 
faring or advantage that such materials become normatively interesting rather than merely inert or fetishized. ${ }^{68}$

For reasons that will be plain in light of the discussion in Part II.C.3 supra, I think that "opportunity for welfare" and "access to advantage" as so described are best understood simply as alternative christenings of resources or wealth. Their advantage over the terms "resources" or "wealth," if such they carry, stems merely from a possibility noted above: that some people have grown numb over time to the fact that resources or wealth, to be resources or wealth as distinguished from unwanted, ethically inert material, are simply opportunities for welfare. ${ }^{69}$ They are modes of access to advantage. Resources and wealth represent, one might say, "material opportunity"-opportunity to satisfy wants, to effectuate plans, to build lives, and to potentially enhance welfare. For the remainder of this piece, I shall use the terms "resource," "wealth," and "material opportunity" by and large interchangeably, with occasional caveats registered where necessary. ${ }^{70}$

\section{Distribution Formulae}

"To distribute," like other verbs, is subject to adverbial

68. See, e.g., Richard J. Arneson, Equality and Equal Opportunity for Welfare, 56 Phil. Stud. 77, 80 (1989) (arguing that the idea of equal opportunity for welfare is the best interpretation of the ideal of distributive equality); Richard J. Arneson, Liberalism, Distributive Subjectivism, and Equal Opportunity for Welfare, 19 Phil. \& Pub. Aff. 158, 159 (1990) (arguing that, for the purposes of determining what should count as fair shares from the standpoint of distributive justice, the appropriate measure of a person's resources is some function of the importance those resources have for that very person as weighted by her conception of her own welfare); Cohen, supra note 55. An analogue in the case of welfare would be someone suggesting we use "ethically compatible preferences" instead. Just as the term "welfare" already connotes such conditions (in contrast to "satisfaction" or "utility"), the word "resources," I am claiming, already connotes the conditions I note here.

69. Rather as some seem to have grown numb to the fact that well-being is not ethically unevaluated pleasure.

70. These caveats concern the distinction that one must draw, in some cases, between what I will call "ethically exogenous" and "ethically endogenous" resources, wealth, and opportunity. Ethically exogenous holdings are those one is not responsible for. Ethically endogenous holdings are those one is responsible for. The discussion of distribution formulae, below, elaborates the normative significance of this distinction. The relevance of the distinction at present is simply that the terms "material opportunity" and "resource" may immediately connote ethical exogeneity to many, while "wealth" probably does not. 
modification. Distributive claims effectively mandate conformity to one or another such modification. They say, in effect, "things should be distributed thus . ..." Such mandates are themselves in turn subject to feasibility constraints that figure into further adverbial modifications, such as, "things can be distributed thus . . .." In sum, then, we ask both "how ought?" and "how can?" The class of possible replies to the second question effectively constrains plausible replies to the first.

In posing the first question, we are asking for specification of what I call a "distribution formula." In posing the second question, we ask for specification of what I call a "distribution mechanism." I treat the first here, and the second in Part III.

Historically there have been three leading candidate families on offer as distribution formulae. I call their advocates "maximizers," "maximiners," and "egalitarians," of one stripe or another. Each family is best known through one or two of its historically most influential member formulae. Each also has featured one or more member formulae argued for by appeal to hypothetical veiled choice scenarios. Accordingly, I will first discuss each of the distinct families of candidates by reference to its best known members. Then I will briefly discuss veiled choice scenarios as employed in respect of all three. I will conclude with (a) observations on the possible combinations of maximizing and equalizing formulae, and (b) observations on the distributional equivalence of many formulae with differing "mixes" of variable-valuations.

\section{Naïve Maximization}

The best known maximizing distribution formulae on offer are those I call "naïve" maximizing formulae. ${ }^{71}$ The operative ideal behind such formulae is disarmingly simple. It is that whatever is distributed should be distributed in such a manner as maximizes the quantity of some aggregate thing assumed to be normatively salient.

71. Strictly speaking, maximization can no more be a mere distribution formula than welfare can be a literal distribuendum. Instead, maximization, like welfare, serves as a touchstone or focal point. The idea is to distribute in such manner as will maximize some aggregate, just as, in the case of welfare-asdistribuendum, one is to distribute something other than welfare in such manner as produces welfare in distribuees. For this reason it turns out, as claimed in the Introduction, that maximizing and equalizing formulae are interformulable. See infra Part II.D.4. 
Typically, that means somehow-aggregated wealth or welfare, summed over the distribuees who hold or enjoy it. ${ }^{72}$ If distribution $D 1$ yields aggregate wealth or welfare $W 1, D 2$ yields $W 2$, and $W 2$ exceeds $W 1$, then $D 2$ ethically dominates $D 1$ on this view. Our goal, simply put, is:

$$
\underset{1 n}{\operatorname{Max}} \sum_{n} W i
$$

where " $i$ " indexes by distribuee and " $n$ " designates the number thereof in the society in question. ${ }^{73}$

Maximization in so unalloyed a form has, unsurprisingly, provoked objections. These include charges of (a) fetishism, (b) objectionably unequal treatment of distribuees, (c) objectionable treatment of distribuees as nonresponsible patients, or less often (d) some combination of these. ${ }^{74}$ It is insufficiently observed, I believe, that the combined objection, (d), is analytically the most satisfactory. For the separate objections are not independent. One tends conceptually to entail the others, as we will now demonstrate.

The fetishism charge is more typically aimed at naïve wouldbe wealth-maximizers than welfare-maximizers, though this fact reflects a confusion that should be unveiled. The idea is that maximizing wealth for its own sake, without proper ethical regard for wealth-makers and -takers, is ethically indistinguishable from maximizing, say, the quantum of blue-colored surface-area in the universe. There seems no ethically cognizable reason for such pursuit if it does not entail proper treatment of distribuees person by person. And if it is indeed individuals who ultimately matter to us, then what constitutes proper treatment of individuals should be explicable

72. Welfare aggregation and maximization are associated with utilitarian ethics. Wealth maximization is associated with normative economics of law. See infra Part III.A.

73. Please bear in mind that this is the form of "naive" maximization formulae. I will discuss departures from the basic form as we proceed. See also supra note 14.

74. See, e.g., Dworkin, supra note 36 , at 11-64 (evaluating the merits and problems of distributional equality with utilitarianism); Sen, supra note 42, at 468-71 (discussing the weaknesses of welfarism from an egalitarian perspective); see also Markovits, supra note 36, at 2295 (arguing that egalitarianism should nullify the differential impacts of luck, and pointing out the differences between "patients" and "agents" of welfare). 
without reference to any aggregate; it must be independently specifiable. $^{75}$

Though it is less often, if indeed ever, observed, naïve welfare-maximizing is subject to precisely the same charge of fetishism as is naïve wealth-maximizing. Welfare might well beindeed might stipulatively or otherwise trivially be- "what matters" to people. But if produced by means that are indifferent to the proper identification and treatment of numerically distinct, politically equal distribuees, it is no less ethically inert than is wealth or blue surfacespace. For again, normative concern for individuals requires attention to the deserved or earned wealth or welfare of each equalrights-bearing citizen, one by one. Individualist normativity takes no cognizance of any antecedently defined aggregate-even a welfare aggregate-in terms of which individuals' rights are but posteriorly defined and apportioned. To hold otherwise is to hold that the aggregate's distribution does not normatively matter, hence that individuals and their political equality do not matter. ${ }^{76}$ And that is precisely what is fetishist.

The unequal treatment charge leveled at naïve maximization is, in view of the foregoing, readily seen to be deeply connected to the fetishism charge. It stems from the possibility that whatever is maximized might be maximized by means that effectively treat persons as being of ethically differing status, even before or apart from their responsible choices. ${ }^{77}$ It can in theory turn out, for example, that aggregate welfare or wealth would be maximized simply by euthanizing faultless depressives or handicapped persons. ${ }^{78}$ Or it might be that maximization would be best effected by channeling resources or wealth toward persons blessed with high endorphin counts or otherwise highly resource-responsive welfare

75. For a reminder of the basis of this supposition, see supra notes 14 and 15 and accompanying text.

76. Some such intuition underlies Robert Nozick's “utility monster" objection to utilitarianism. It is not accidental that Nozick commences his preface with the observation that "[i]ndividuals have rights." See Robert Nozick, Anarchy, State, and Utopia ix (1974) (analyzing the nature and functions of the State, and advocating for limited government involvement).

77. In such cases we might say they are treated as being "antecedently" or "exogenously," hence ethically essentially unequal.

78. Richard Posner professed in the early 1980s to be troubled by this possible consequence in the case of welfare-maximization, but then puzzlingly dismissed the concern in the case of wealth-maximization. See infra Part III.A. 
functions. Those would be people who, like Benedict in the Introduction, derive disproportionate pleasure from what they receive. ${ }^{79}$ It is argued that the fact that naive maximization imperatives do not prohibit such measures in principle-and indeed seem to welcome them-demonstrates maximization's unsuitability to the task of articulating an ethically defensible distribution formula. ${ }^{80}$

The patient-treatment objection to naïve maximization is the flipside of the unequal treatment objection. It is, like the unequal treatment objection, also conceptually wedded to the fetishism objection. The patient-treatment objection states that distribution effected on the basis of morally arbitrary features of faultlessly disadvantaged persons ${ }^{81}$ does more than treat such persons as effectively expendable and non-rights-bearing. It also treats morally arbitrarily advantaged persons ${ }^{82}$ as being of meritlessly higher ethical or political status. And, crucially from the vantage of this objection, it does so quite apart from the quality which constitutes the beneficiaries as fellow persons-their responsible human agency.

There is a deep sense in which naïve maximization is, so to speak, "metaphysically" patronizing. The advantage enjoyed is as disturbingly contingent, and in consequence alienating and demoralizing, as one's birth into a right to larger distributive shares than those enjoyed by others is the product of a dubious "blessing." It is effectively her birth into a polity that treats her as a patient and, indeed, as an object. For she is treated as one whose politically honored advantages are not really her own-not the product of her agency-but instead a conditional gift conferred by society in virtue of an accident. They are conferred simply because the beneficiary is, so to speak, "productively blonde." ${ }^{83}$ In such a polity she is only

79. See Nozick, supra note 76 , at $232-46$ (examining issues of equality, welfare distribution and the obligations of the state).

80. Probably the best known instance of this argumentative tack is Nozick's "utility monster" objection to utilitarianism. See Nozick, supra note 76, at 241 . It is no answer to say that this does not typically happen in practice. Normativity concerns not happy accidents, but principles.

81. For example, depressives and handicapped persons, as just discussed.

82. Nozick's “utility monsters" and talent-Übermenschen (the wealthily born among us), for example.

83. Imagine a society in which blondes were so rare that birth with blonde hair was viewed as a sign from the gods. A rare blonde is in consequence treated as an avatar, maintained in a temple and endowed with sacramental gifts. Is there not an obvious sense in which such "lucky winners" would experience 
contingently favored-an accident of birth. She is a mere funnel into which the channeling of resources simply happens to produce a higher aggregate. That, it can be argued, is deeply disrespectful and ultimately harmful to our conceptions of ourselves, both for the fortunate and unfortunate alike. ${ }^{84}$

A final objection to naïve maximization is rooted in measurement challenges of the kind surveyed above in II.B.1. Where welfare is held out as maximandum, the objection is that welfare, in the abstract, is not sufficiently amenable to comparison in the holding as to provide the idea of "maximization" with content. Where wealth is the proposed maximandum, the measurement rooted objection finds its ground ultimately in commensurability. One objects that the absence of markets in many valued or potentially valued goods and services-including risk-bearing services-renders the "wealth" that is maximized an ethically incomplete index. Or, relatedly, one points to one or another variant of the so-called "Scitovsky paradox" and concludes that, since two states of the world can be superior to one another according to the Kaldor-Hicks principle, and since the Kaldor-Hicks criterion accordingly does not yield an ordering, "wealth" is not sufficiently determinate an aggregate as to be amenable to intelligible maximization. ${ }^{85}$

themselves as freakish, radically separated off from others? The sense in which this is damaging to the putative beneficiary will be familiar to those who have read of the psychological damage experienced by many members of royal and celebrity families. It is also a staple of fiction concerning the longings of celebrities, royalty, avatars and even angels to lead ordinary lives. See, e.g., Mark Twain, The Prince and the Pauper (1882). Also such films as The Last Emperor, Roman Holiday, and Wings of Desire.

84. This is because the favorable treatment is contingent upon morally arbitrary, accidental features, and is impliedly withdrawn immediately upon even accidental loss of such features. Some such intuition as this would appear to underwrite the expressions of alienation, anxiety, and even humiliation sometimes heard from people who are found physically attractive by large numbers of others. Analogous concerns sometimes are registered by opponents of affirmative action programs who have been beneficiaries of such programs. See, e.g., Clarence Thomas, My Grandfather's Son: A Memoir 107 (2007) (discussing how principles of self reliance would do more to lift black people out of poverty than affirmative action policies like quotas). There is a link here to the notion of a "right to punishment" as discussed supra note 34. The link is well drawn in Fyodor Dostoevsky, Crime and Punishment (1866).

85. As Scitovsky shows, if state of the world A can be shown to be superior to $B$, and then $B$ is shown superior to $A$, the two states are not determinately ordered. Such is the "Scitovsky paradox," which Scitovsky shows to be endemic to 
Naïve maximizers offer well-worn rejoinders to these objections. To the fetishism charge, the rejoinder is either that welfare is what matters to people (in the case of welfare-maximizers) or that wealth affords opportunity to satisfy preferences, hence welfare (in the case of wealth-maximizers) ${ }^{86}$ In both cases, it is concluded, maximizing cannot, in consequence, be fetishistic.

This rejoinder is a non sequitur. The fetishism charge is not that welfare and wealth do not matter. ${ }^{87}$ It is that their naïve maximization does not matter. It is that naïve maximization misunderstands the ways in which welfare and wealth matter... As themselves, these of course matter by definition to everyone. But as maximized pursuant to a merely additive maximizing formula, they at best matter only, or objectionably disproportionately, to those lucky enough to attract distributions that are wealth-productive for them. Welfare or wealth will not in such case matter to "us," whose collective role is that of evaluating a distribution formula's ethically appropriate treatment of each rights-bearing constituent member of the distributing polity that we jointly constitute.

To the unequal- and patient-treatment charges, naïve maximizers also have offered rejoinders that amount to non sequiturs. In the case of the unequal treatment charge, the rejoinder

would-be orderings attempted along a Kaldor-Hicksian "compensation" or "wealth" metric. See Tibor Scitovsky, A Note on Welfare Propositions in Economics, 9 Rev. Econ. Stud. 77, 88 (1941); see also Jules L. Coleman, Efficiency, Utility and Wealth Maximization, 8 Hofstra L. Rev. 509, 513-16 (1980) (analyzing the merits of Pareto utilitarianism and its implications for social welfare). The determinacy objection is also grounded in distribution. See infra Part III.A.

86. See, e.g., Richard Posner, The Economics of Justice 88-103 (1983) (exploring the ethical and political basis of wealth maximization and explaining the wealth maximization efficiency of Kaldor-Hicks efficiency); Arneson, Equality, supra note 68, at 77 (arguing that "the idea of equal opportunity for welfare is the best interpretation of the ideal of distributive equality").

87. The rhetorically rich but perhaps overstated title of a well-known article by Dworkin might be partly responsible for this misunderstanding. See Ronald Dworkin, Is Wealth a Value?, 9 J. Legal Stud. 191 (1980); see also infra Part III.A. The misunderstanding itself permeates Dworkin. See Bruce Johnsen, Wealth Is Value, $15 \mathrm{~J}$. Leg. Stud. 263, 269 (1986) (arguing that a broader definition of "wealth" encompassing non-material goods can inform the misunderstandings in the Posner-Dworkin debate).

88. See Hockett, Why Parestians Can't Prescribe, supra note 13, at 85 (noting that 'how [one] weights differing persons' individual satisfaction functions in computing a social welfare aggregate will determine who [one] thinks should receive what scarce resources in what amounts"). 
is that maximization counts each person's utility or wealthproduction function for one in the global welfare function. ${ }^{89}$ One individual function, the claim runs, one "vote," hence equal treatment. We encountered this "Hail Mary" play above, in the Introduction..$^{90}$

The reply is a non sequitur for reasons also noted in the Introduction. It unethically reduces distribuees to their welfare or wealth-production functions. That mis-identification amounts to a form of fetishism with respect to distribuees that is on all fours with the fetishism of naïve maximization with respect to distribution formulae. One is no more one's wealth- or welfare-function than one is one's nose. If people are both faultlessly and non-creditably born with different such functions, ${ }^{91}$ then equal treatment of those functions is unequal treatment of those persons who are born with them. And it is precisely that, in effect, which is of concern to those who level the unequal treatment objection. ${ }^{92}$

To the treatment-as-patients objection, the rejoinder is that, since distribuees are boundedly autonomous agents who act partly to produce their own welfare or wealth, and since distributing so as to maximize welfare or wealth is to distribute disproportionately to the best, "most efficient" such welfare- or wealth-producers, maximization effectively coincides with agent-rewarding. ${ }^{93}$

89. See, e.g., John J. C. Smart, An Outline of Utilitarianism, in John J. C. Smart and Bernard Williams, Utilitarianism: For and Against 32 (1973) (stating the utilitarian principle that an individual counts "neither more nor less than any other person").

90. See supra note 16 and accompanying text.

91. This is true most dramatically, though not exclusively, in the case of congenital depressives and handicapped persons.

92. See Dworkin, supra note 87 (arguing that the normative failures of the economic analysis of law are so great that they cast doubt on its descriptive claims unless these descriptive claims can be embedded within a very different normative theory); Ronald Dworkin, Why Efficiency?, 8 Hofstra L. Rev. 563 (1980) (arguing for a deep equality theory over and against a compromise theory of "trade-offs" between distribution and wealth advocated by Calabresi and Posner).

93. See, e.g., Richard Posner, The Value of Wealth: A Comment on Dworkin and Kronman, $9 \mathrm{~J}$. Legal Stud. 243 (1980) (commenting on Dworkin and Kronman's respective approaches to wealth maximization in relation to his own approach); Richard Posner, Utilitarianism, Economics, and Legal Theory, $8 \mathrm{~J}$. Legal Stud. 103 (1979) (distinguishing utilitarianism from economics and arguing that the economic norm of "wealth maximization" provides a firmer basis for a normative theory of law than does utilitarianism). 
This rejoinder is half right, half non sequitur, and so we shall find it half echoed in what turns out to be the most plausible characterization of the correct distribution formula further below. The problem is that it places the cart before the horse, so to speak, and in so doing fetishizes the cart. If distribuees bear rights to equal treatment as agents ex ante, prior to engaging in the actions for which they are responsible, then the "horse" should be distribution considered prior to the consequences for any ex post aggregate. For that aggregate is as much the product of agents' responsible actions as it is of the ex ante distribution. Attend to the propriety of the latter, then, and the appropriate aggregate - the nonfetishist, ethically cognizable aggregate-will effectively take care of itself: it will be maximized quite "automatically," ex post by responsible agents, as the output of their actions upon the correctly, ex ante distributed inputs. ${ }^{94}$

Maximizers do not appear to have arrived at a canonical rejoinder to the measurement-rooted objections to maximization. I believe that is no accident. The key to an answer lies in turning away from the assessment of distributive welfare-outputs altogether, in favor of the assessment of distributive resource-inputs. Once we do that, ready answers to all measurement challenges are immediately forthcoming. I will defer elaboration on that point to Part II.E, on distribution mechanisms.

\section{Prioritarian Maximining}

Prompted by some of the shortcomings of naïve maximizing just discussed are "prioritarian" views, a recently influential family of candidates for distribution formula. We shall see that they are not, however, adequately responsive to these shortcomings. Probably the best known prioritarian distribution formula is also one of the earliest. I refer to the "maximin" formula defended most thoroughly by John Rawls. ${ }^{95}$ Rawls and additional prioritarians argue that many of the differences among persons that effectively recommend

94. Cognate observations apply to those maximizers who observe that maximizing might tend to coincide with equalizing in view of the diminishing marginal utility of wealth, or of whatever else is distributed. Quite apart from the claim's ignorance of responsible agency and its reliance upon the happy accident of concavity, it invites the question: If you are serious about equality, why bother with naïve maximizing at all? See infra Part II.D.4.

95. Rawls, A Theory of Justice, supra note 64. 
disparate treatment are, as Rawls put it, "arbitrary from a moral point of view." Rawls concludes that such differences should not be distribution-determinative, precisely because they are morally arbitrary. ${ }^{97}$ If we are to treat one another as moral equals, these differences must be compensated for, so as not to place people at a relative disadvantage.

Neutralizing such differences altogether, Rawls seems to have recognized, would result in our pursuit of an egalitarian distribution formula of some sort. ${ }^{98}$ Indeed, it might even result in an outcome-egalitarian formula, though this is not clear. ${ }^{99}$ But Rawls shied away from full-bore egalitarian distribution of any sort, on the theory that some departures from equality might render even the "worst-off" among unequals "better-off" than they would be under conditions of equality. In consequence, Rawls concluded, departures from equal distribution are morally tolerable if, but only to the degree that, they tend to better the lot of "the worst-off."100

Rawls labeled this Grundnorm "the difference principle."101 If naïve maximizing is tide-raising, and if a rising tide not only lifts all boats but lifts them so high that the lowest are raised higher than they would have been under an egalitarian distribution formula, then we might say maximization will be ethically permissible. But it will be so only on condition that-and differing egalitarian distributions will be globally preference-orderable precisely according as-"the minimum" is maximized too. The aim, then, is:

$$
\underset{1 n^{*}}{\operatorname{Max}} \sum_{i}
$$

where " $i$ " again indexes by distribuee and " $n$ " designates the best-off member of the worst-off class, hence the cut between "worst-off class"

96. Id. at 72 .

97. Id. at 86-93.

98. Id. at $12-19,52-56,86-93$.

99. The sense in which it's not clear will emerge presently.

100. There's quite a leap here. But I aim here to exposit, not defend, Rawls's chain of reasoning.

101. Rawls, A Theory of Justice, supra note 64, at 65-68. By a "Grundnorm," I mean a "basic," or "founding" principle-a fundamental value from which other values derive. I take and adapt the term from Kelsen. See generally Hans Kelsen, Pure Theory of Law 55 (1928) (employing the term to designate a foundational rule from which other rules in a legal system ultimately derive their authority). 
and all others. Maximin is accordingly the formulaic upshot of Rawls's difference principle.

Both the difference principle and maximin turn out, on reflection, to be only a bit better than non sequitur responses to Rawls's specific objections to naïve maximization. They turn out in consequence to be rather cruderemedies, if indeed determinate remedies at all.

For one thing, "the worst-off" class is quite indeterminate: Not only is it unclear whether it is the worst off person, the worst off $0.1 \%$ of persons, the worst off centile or decile or quintile or some other percentage. In addition, it is unclear even how we are to decide. No principles are on offer, nor does any particular rationale seem to offer itself. ${ }^{102}$ That is a bit troubling, given that maximin is meant to neutralize morally arbitrary determinants of distributive shares, and thus afford ethically satisfactory guidance to lawmakers.

A closely related difficulty is that the idea of the "worst-off class" does not even seem to be clearly conceived or intelligibly motivated, let alone defined, by Rawls with any view to the reasons for anyone's being worst off. ${ }^{103}$ Rawls draws no distinction, for example, between those who are worst-off by chance and those who are in effect worst-off by choice, say owing to self-destructive behavior, for example. ${ }^{104}$ Yet if any distinction of interest to distributional evaluation is not "morally arbitrary,"-and surely there must be some that are not if the predicate is to do any workone would think it would be that one.

Why, then, do Rawls and other prioritarians not consider such questions in connection with "the worst-off" and their proposed distribution formulae? No answer is forthcoming. ${ }^{105}$ That is strange

102. Rawls's failure to offer a basis on which to make the cut does not seem to me accidental. There is no principled basis. And that, I believe, stems directly from the difference principle's failure directly to address its own motivating concern-the concern with morally arbitrary distinctions among persons that result in their differential faring. The only principled means of addressing that concern, in turn, not only supply a satisfactory theoretical baseline, but also render the difference principle itself quite superfluous. Rawls thus emerges as an unstable resting point en route from naïve to ethically cognizable maximizingor, in other words, from ethically non-cognizable to ethically cognizable equalizing. See infra Parts II.D.3, II.D.4, III.A.2.

103. Rawls, A Theory of Justice, supra note 64 , at 83-84.

104. Id.

105. Id. 
and troubling, particularly given Rawls's own proffered reasons for abandoning naive maximizing. ${ }^{106}$ For insofar as there is divergence between those who are responsibly worse-off on the one hand, accidentally worse-off on the other, maximining looks no less "morally arbitrary" than naïve maximizing. Both maximize morally arbitrarily; they differ only in maximizing different maximanda. That means in turn that maximining no more treats distribuees as moral equals and responsible agents than does maximization.

Almost as if to register that he was at least obliquely aware of these problems, Rawls's full theory of appropriate distribution employed two more devices apparently meant to bring a modicum of responsible agency and equal treatment back into the account. The first device was the familiar "veil of ignorance" alluded to earlier. ${ }^{107}$ Rawls's claim here was, in effect, that in their roles as distributors, distribuees "would" select maximin, assuming they did not know in advance whom they eventually "would" become. ${ }^{108}$ In this case, choosers would be prevented from choosing to benefit themselves over others because features distinguishing them from others would be behind the veil, hidden from view. What perhaps was recognized less explicitly, however, was that the veiled choice would render maximin at least partly a responsible choice, as well. Conditions could be attributed in part to a choice that Rawls asserts "would" be made by anyone behind the veil. If so, choosing agents could be appropriately held to the choice. The degree to which this veiled choice scenario prompted Rawls is unclear. Conceivably, it constituted at least part of his theory's attraction, consciously or otherwise. I say this for two reasons. First, because of the relationship between ethical equality and responsible agency, noted above: The veil imposes impartiality and then holds the choosers responsible for choices they "would" have made from behind it. Second, because of the language Rawls used in motivating the second responsibility-sensitive wrinkle to which I have alluded: his selection of distribuendum. On, now, to that.

The second way Rawls addressed the responsible agency and ethical equality problems afflicting his difference principle was through his characterization of the appropriate distribuendum.

106. Id. at 86-93.

107. Id. at 118 .

108. The reason for the scare-quotes around "would" will emerge momentarily. 
Rawls prescribed distribution of what he called "an index of primary goods"-in effect, a lumpy and only partly scalable vector of disparate, broadly conceived resources. ${ }^{109}$ Apparently, Rawls was cognizant of the agency/equity value this prescription offered. First, his explanations made some overt references to the fact that the selection of primary goods as distribuenda effectively held distribuees partly responsible for the production of their own welfare. ${ }^{110}$ Second, Rawls expressly noted that treating primary goods as distribuenda required distribuees to internalize the costs that their preferences for primary goods imposed upon others. ${ }^{11}$ In his brand of distributive maximining, Rawls seems to have been at least an incipient proponent of responsible agency in the theory of justice.

Rawls's shortcoming lies in that incipience. Primary goods as distribuenda need not bear any connection to maximin as a distribution formula. Indeed, those primary goods amount to little more than a clumsy and ultimately incoherent graft-on. They render Rawls a responsibility-tracer in respect of his distribuendum selection, yet a moral accident-allower in his selection of distribution formula. ${ }^{12}$ Why? Because the "worst off" in respect even of primary goods might be poorly off either by chance or by choice. ${ }^{113}$

109. Rawls, A Theory of Justice, supra note 64 , at 54-55, 78-81, 348, 35865. In light of the incomplete scalability, the index is but incompletely an index. See supra Part II.C.1; see also Hockett \& Risse, supra note 64.

110. Or, in Rawls's preferred idiom, the formulation and successful pursuit of their own "plans of life." See Rawls, A Theory of Justice, supra note 64, at 7980 .

111. Id. at 359 .

112. This is not surprising given Rawls's ambivalence about responsibility. On one hand, he defends his selection of primary goods as distribuendum by reference to the importance of responsibility. On the other, he at times argues deterministically (and confusedly) that people are not responsible unless they can choose freely, and that they cannot choose freely because they do not choose their faculties for choosing. See Rawls, A Theory of Justice, supra note 64, at 90-93, 182.

113. See, e.g., Richard Arneson, Primary Goods Reconsidered, 24 Noûs 429, 429 (1990) (addressing the argument asserted by Rawls's challengers "that using primary goods shares to compare individual situations is unfair to those individuals for whom primary goods will not be particularly useful for the successful pursuit of their life plans," and concluding that "a principle of distributive justice ought" not "to use primary goods as the basis of interpersonal comparisons ["). If leisure was considered a primary good, we would not be able to say that voluntary non-workers, poor in other primary goods, were poorly off. 
Theoretically, the treatment of maximin as a product of veiled choice might have rectified, to some degree, the paradox noted in Rawls's theory-particularly if the choice had been made, or if there were reason to suppose it would have been made. But the choice theory implied by Rawls's selection of maximin as distribution formula is "exotic" at best. ${ }^{114}$ At least with regard to preference schedule, the choice Rawls's selection imputes is extensionally equivalent to the choice that would be made only by those who are infinitely risk averse. ${ }^{115}$ Accordingly, there is little reason to suppose the choice even would be made, let alone has been made. Hence, the choice theory affords little responsible agency to Rawls's characterization of the appropriate distribution formula.

In sum, Rawlsian justice theory seems an unstable mixture of agent/patient and responsibility-tracing/accident-permitting, distributive-ethical prescription. And maximining-the distribution formula that gives partial expression to that mixture-appears as ethically arbitrary as the naïve maximizing it is meant to supplant.

\section{Equalizing: Naïve and Sophisticated Varieties}

There are a number of proposed egalitarian distribution formulae. ${ }^{116}$ Some of these can be viewed as purifications of original Rawlsian insights, others not. As we shall see, proposals of the former, sophisticated sort may also be characterized as more ethically plausible forms of maximization. ${ }^{117}$ Proposals of the latter

114. See John E. Roemer, Egalitarianism against the Veil of Ignorance, 99 J. Phil. 167, 168 (2002) (referring to Rawls's "exotic decision theory").

115. See, e.g., Kenneth J. Arrow, Some Ordinalist-Utilitarian Notes on Rawls's Theory of Justice, 70 J. Phil. 245, 253-54 (1973) (critiquing Rawls's concept of primary goods as inadequate for reaching accurate interpersonal comparisons); Leonid Hurwicz, Optimality Criteria for Decision Making Under Ignorance, 370 Statistics 1, 1 (1951) (theorizing that "if certain properties are assumed for the optimality criterion ... then an action must be evaluated merely in terms of the best and worst it may accomplish"); Geoffrey A. Jehle \& Philip J. Reny, Advanced Microeconomic Theory 260 (2d ed. 2001) ("Rawls's own argument for the maximin over the utilitarian rests on the view that people are risk-averse. But this cannot be a wholly persuasive argument . . . Rawls' maximin criterion ... can be seen as a very special case ... that arises when individuals are infinitely risk averse.") (emphasis in original).

116. See, e.g., Cohen, supra note 41; Dworkin, supra note 36; Sen, supra note 55; Arneson, Equality and Equal Opportunity for Welfare, supra note 68.

117. See infra Part II.D.4. 
naïve variety suffer from the same flaws as do naïve maximizing and Rawlsian prioritarianism as explained below. ${ }^{118}$

The concept behind the more sophisticated proposals can be articulated in the following way: Suppose that some differences among persons were partly causative of their differential faring, yet "arbitrary from a moral point of view." satisfactory distribution formula simply would partition each person's holdings into portions $R i$, traceable to moral arbitrariness, and $1-R i$, traceable to responsible agency. The formula would then mandate equalization of $R i$, while facilitating agents' own maximization of $1-R i$.

The morally arbitrary portion of any one person's holdings, $R i$, would be valued invariantly across all persons $i$. The nonarbitrary portion, $E i$, would be permitted-indeed, required-to vary among persons according to the degrees of responsible effort they expend on productive activities valued by a market comprising themselves and others. ${ }^{120}$ The distribution formula could be expressed as:

$$
\forall i: H i=E i+R i=E i+R / n
$$

where " $\forall i$ " is "for all $i$," " $H i$ " designates each person $i$ 's holdings, " $n$ " is the number of persons $i$, and " $R / n$ " designates the constant that is each $i$ 's pro rata share of the exogenously given residuum, $R .{ }^{121}$

$R$ could be called "luck"; "ethically exogenous resources"; "ethically exogenous opportunity"; "the exogenous endowment";

118. Id.

119. See Rawls, A Theory of Justice, supra note 64, at 86-93.

120. In that case, leisure would not count as part of one's "holdings." Were we to count leisure as part of one's holdings, we would say that $E i$ 's composition, rather than $E i$ itself, varies across persons $i$. One consequence would be that maximization of the full vector of goods one enjoys "takes care of itself," as a straightforward consequence of responsible choices made by distribuees as to the disposition of their resource endowments- $R i$. Implications of "varying degrees of responsible effort in activities varyingly valued by themselves and others" are traced and treated below. The basic idea is that any surplus you end up with over your mandatorily equalized, ethically exogenous endowment is properly a matter of what others give you in exchange for what you give them. This proves particularly important in the treatment of distribution mechanisms infra Part III.B.

121. $R$ would be the sum of each person $i$ 's $R i$. That is, $R=\sum R i$. Here, summing requires commensuration and interpersonal comparability. 
and "the responsibility-indifferent residuum," among others. Accordingly, those who would equalize $R i$ across persons could be labeled "luck egalitarians," "resource egalitarians," "responsibilitytracing egalitarians," "opportunity egalitarians," and so on. I shall call them "opportunity egalitarians" for reasons analogous to those offered supra Part III.B.3, in treating "resources," "opportunity for welfare," and "access to advantage" as variants of "material opportunity."

Most adherents to opportunity egalitarianism regard Rawls as an incipient opportunity egalitarian. ${ }^{122}$ To them, Rawls simply had not managed fully to purge his views of the naïve utilitarian maximization imperative, which he sought to replace with an individualist distributive-ethical ideal. A full purge consistently would treat distribuees as boundedly responsible agents, distribuenda as fully indexed goods and services rather than lumpy Rawlsian "primary goods," and the correct distribution formula as that which distributes goods and services in a manner that is systematically responsive to the boundary between faultless chance and responsible choice.

Opportunity egalitarians are not without challenges. That cut between chance and choice, or " $R i$ " and " $E i$ " above, can be difficult to draw for a number of reasons. ${ }^{123}$ In addition, there are problems of commensuration, which plague any distribution mode that takes as distribuenda a variety of material goods and services. Particularly troublesome is the fact that opportunity egalitarianism confronts head-on all morally arbitrary determinants of wellbeing. But among those determinants are such deeply personal or internal resources as talents and handicaps. This means that to be thorough and consistent, opportunity egalitarians require some means of

122. See, e.g., Samuel Scheffler, Philosophy and Politics, 21 Phil. and Pub. Aff. 299, 321 (1992) ("Rawls's claim is that just institutions need make no special provision for expensive preferences . . . because people living in a just society have the capacity to adjust their preferences in light of the resources they can expect to have at their command.").

123. See generally Robert Hockett, Whose Ownership? Which Society?, 27 Cardozo L. Rev. 1, 74-75 (2005) (arguing that, if ethical holdings or entitlements are examined prior to an individual's entry into the market, subsequent violations of these holdings by chance or choice may raise different questions about how to compensate for the harm); Robert Hockett, $A$ Jeffersonian Republic by Hamiltonian Means, 79 So. Cal. L. Rev. 45, 59 (2006) (describing the difficulties in drawing the boundary between ethically endogenous choice and ethically exogenous circumstance, among others). 
equalizing these personal resources and deficits along with all external inputs to welfare functions. ${ }^{124}$ That task appears difficult.

Nevertheless, these challenges merely reduce slightly the clear and significant advantages afforded by opportunity egalitarianism. The opportunity egalitarian principle straightforwardly coheres with the view of distribuees as ethically equal, boundedly responsible agents, as discussed above at II.B. It shows better fit with that construal of distribuees than do naïve and prioritarian maximizing, and naïve equalizing, as we will see below. Likewise, it coheres with the view of appropriate distribuenda as material inputs to individual welfare. That is, it better fits the construal of appropriate distribuenda as material opportunities. The same cannot be said for other proposed naïve egalitarian distribution formulae, as I will now show.

Competing positions, or naïve maximizing and maximining, do not even attempt to reap these advantages. In consequence, they remain not merely practically but foundationally short of the unquestioned ideal.

Some utilitarians, for example, have argued for wealth equalization quite apart from any consideration of distribuees' ethical equality or responsibility for wealth- or welfare-production. To that end, they posit first that the utility functions are roughly the same for all people, and second that the marginal utility of wealth is diminishing per those functions. ${ }^{125}$ If true, these conjectures suggest that rough equalization of holdings would maximize aggregate welfare.

Like all forms of utilitarianism, this view treats distribuees as patients. It takes us for ethically inert, automatically operating welfare manufactories into which wealth is fed, like worms into chicks' beaks. It also treats distribuees as, at best, only contingently equal, and more deeply unequal. For distribuees are treated as

124. This is a challenge, not a fault. Fault lies with views that do not even notice that such "resources" are morally arbitrary.

125. See, e.g., Abba P. Lerner, The Economics of Control 24, 26 (1944) (assuming that "different people enjoy similar satisfactions," and that "the principle of diminishing marginal utility of income holds generally") (emphasis in original); Arthur C. Pigou, The Economics of Welfare 137 (4th ed. 1932) (concluding that if "complete equality among the values of marginal social net products is wanting, a diminution in the degree of inequality that exists among them is likely to benefit the national dividend"). 
equals only in respect of a contingently identical feature, their utility functions. Moreover, responsibly diligent distribuees are expropriated on behalf of, and thereby conscripted for the purposes of, the non-diligent. Only the utility aggregate is valued; the way it is produced does not matter. Finally, this view treats aggregate welfare, not wealth, as the distributive focal point. ${ }^{126}$ In short, then, it remains a contingently income-equalizing version of naive maximization.

Non-utilitarian welfare-egalitarians are another group of equalizers who historically have construed distribuees as patients, and thus ethical non-equals. ${ }^{127}$ They have done so by taking the following positions, which jointly, if unwittingly, give rise to that characterization. First, they acknowledge differing welfare functions across persons. Second, in consideration of that fact, they advocate differential wealth inputs across persons so as to equalize individual welfare outputs. Third, in so doing, they hold distribuees entirely unaccountable for their own welfare. And fourth, as a result, they effectively accept conscription of the diligent to subsidize even the willfully non-diligent, like the utilitarian and wealth egalitarians detailed above. ${ }^{128}$

Some advocates of this position presumably would abandon it, were they fully cognizant of its entailments. Others, perhaps, hold the position because they have some confused metaphysical belief about agency. They are determinists, on which view all persons "really" are patients-patients of God or of fate or of "nature"through and through. ${ }^{129}$

In light of this latter observation, there is a sense in which naïve welfare-egalitarianism can be reconciled with, or even amount

126. It is also another case of putting the cart before horse. If wealth equalizing is sought only for its putative aggregate welfare-maximizing, it is sought in pursuit of a fetish.

127. See, e.g., Lerner, supra note 125; Pigou, supra note 125.

128. Id.

129. I admit to finding it difficult to make sense of this position. By its own criteria it would be prompted in the saying by metaphysical necessity rather than the proponent's free acceptance of the truth. We who hear the claim likewise will do whatever we do as mere effects of the same occult causes rather than in response to reasons. Reason-giving itself, such as determinist claims amount to, seem to presuppose freedom of the only kind that matters-that which underwrites attribution of responsibility. But alas, I must leave the free will problem there for the present. 
to, a degenerate case of the opportunity-egalitarian position. Were it somehow possible for both to intelligibly maintain and empirically establish that nobody is "really" responsible for anything, then welfare-egalitarianism would extensionally coincide with opportunity-egalitarianism. One would simply set $E i$ trivially at zero for all values of $i$ in the formula set out above. This would formulaically express the idea of no one's "really" being responsible for anything, including for any portion of her own holdings. There would then be no ethical point in distinguishing between opportunity-input and welfare-output. I mention this prospect, however, as a mere theoretical curio. I do not see how the antecedent conditions-establishing that we are not "really" responsible for anything-could be satisfied. Even so much as to articulate the position would seem to be self-refuting.

Symmetrical remarks, incidentally, would hold of welfaremaximizing utilitarianism as described above in Part II.C.2. Were it plausible to hold persons responsible for everything rather than nothing - even the entireties of their utility functions-then we might set $R i$ trivially at zero for all values of $i$ in the above-stated opportunity-egalitarian formula in recognition of that "fact." Persons $i$ would be treated as equals by dint of their each counting for one and there being no ethically exogenous residuum, for which they were not responsible, to be spread objectionably unequally. ${ }^{130}$ Again there would be no more point in distinguishing between opportunity-input and welfare-output. Once again, however, the antecedent condition here-distribuees' being responsible for everything-looks impossible to maintain. We seem to be stuck with the cut-that between chance and choice-the recognition of which is opportunity-egalitarianism's theoretic blessing and (largely surmountable) pragmatic curse. ${ }^{131}$

A final point that bears noting has to do with equalization's relation to fairness. "Fairness," on all semantically informed understandings of the word, connotes impartiality or even-

130. On such a view you could presumably be held responsible for your forehead height too. You'd be responsible for everything. Hence you could be identified with everything, which is another reason, I suppose, to call people like the early utilitarian Sidgwick "eyes of the universe." See Bart Schultz, Henry Sidgwick: Eye of the Universe, An Intellectual Biography (2004). III.

131. "Largely surmountable," again, for reasons that emerge infra, Part 
handedness: ${ }^{132}$ Commonly proffered synonyms of "fair" include "equitable," "just," "impartial," "unbiased," "even-handed," "treating like cases alike," and the like. ${ }^{133}$ To treat parties fairly is to treat them as equals for purposes of the treatment. It is to eliminate or neutralize inequities that are exogenous to the purposes of the treatment, and to retain or vindicate inequities that are endogenous to the purposes of the treatment. These benefits and burdens would be distributed in proportion to their connection to the purposes of treatment.

Say, for example, that the purpose of the treatment in a particular context is to distribute in accordance with responsible human agency and nothing else-i.e., no morally arbitrary feature of the distribuees. Then fair treatment in this context will be that which allocates value to distribuees in proportion to their creditability for value, or their level of production. ${ }^{134}$ It will also, then, a fortiori, be treatment that equally allocates value for the attributes which no one is responsible for, since everyone is equally not responsible for that remainder. (Zero equals zero, across the full population.) Fair allocations, in short, will be those that equalize holdings of such stuff as no one is responsible for, and require holdings for which persons are in fact responsible to vary in proportion to their responsibility. If this is so, then the class of fair allocations would seem to be precisely the class of opportunityegalitarian allocations.

\section{Interformulability}

The immediately foregoing discussion of distribution formulae suggests an obvious formal means of rendering the point with which I introduced this Article. I said that to maximize one thing is to distribute another thing and to equalize yet another thing-the latter thing amounting, in turn, to some attribute with which we identify distribuees. The observation made just above, that certain equalization formulae can be construed as degenerate cases

132. It bears virtually no recognizable relation, incidentally, to Kaplow \& Shavell's proffered definition in their book cited supra note 1.

133. See, e.g., Black's Law Dictionary 595 (6 $6^{\text {th }}$ ed. 1990).

134. "In proportion to . . . creditability for value-production" requires, if it is to bear content, commensuration of disparate items and services, then cardinal valuation of agents' inputs along the resulting index. For an illustration of this point, see infra Part III.B. 
of maximization formulae and vice versa, amounts to a further corroboration of the point. Let us now generalize it formulaically.

The following translation rule captures the basic idea. For any aggregative maximizing imperative of the form:

$$
\operatorname{Max} \sum u i
$$

in which $u$-factors are summed, simply translate the summand, $u i$, into its counterpart equalisand, $u i^{*}$, and state the imperative thus:

$$
\forall i: \operatorname{Eq}\left(u i^{*}\right)
$$

where " $\forall i$ " is read, "for all $i$," and "Eq" means to "Equalize" just as "Max" means to "Maximize." In short, rather than summing $u$-factors and maximizing the sum, we enjoin functionaries, equivalently, to equalize the summand's egalitarian counterpart, $u^{*}$. Since there is always a counterpart, we are always able to work the translation. ${ }^{135}$

Two brief, concrete examples will make the point plain. Suppose first we are garden variety utilitarians. We accordingly wish to maximize aggregate utility. We aim, then, to maximize the sum of $u i$-measures over individuals $i$. The summand in this case is each individual's "welfare," or "utility" measure, as ordinarily construed by utilitarians. Each individual's utility function receives equal weight in the global welfare function, a weight of one. That weighting is accordingly what the global welfare function equalizes. Precisely this point is what underwrites some utiltiarians' claim to be egalitarian, as we noted earlier. ${ }^{136}$

What these same utilitarians appear not to have noticed is that the feature in virtue of which a global welfare function treats individuals as equals, or their utility functions, is also the attribute with which those who act in conformity with the function identify or "count" individuals for policy purposes. The global welfare function "reduces" counted individuals to their utility functions. That reduction might not cohere very well with our view of distribuees if, say, we construe them as boundedly responsible agents per the emergent consensus discussed above in II.B. This points the way to a second example that can instructively be compared to the utilitarian.

135. Though of course conceptual and idiomatic dexterity would be required in many cases, in some of which there would be little more than theoretical interest in the translation exercise.

136. See supra note 116 and accompanying text. 
Suppose we object, then, to utilitarianism by dint of the way it construes us in our capacity as distribuees. What it had set before us to maximize-"utility"-sounded inoffensive enough on first blush, if for no other reason that it was vague and mysterious. But then we find, upon further analysis, that what it effectively tells us to equalize and identify ourselves with is out of sync with what we know ourselves to be. It misidentifies that feature of ourselves in virtue of which we legally and politically matter. How, then, to give formal expression to our amended view of what law and policy should be directed toward?

Here is the proverbial kicker: We can give formal expression to what we take for a more satisfactory legal and policy imperative in precisely the same schematic terms as the utilitarian did. We simply convert what we take for the more appropriate form of individualidentification and equalization-i.e., the better construal of distribuees and distribuenda, into a maximizing formula. We proceed, that is to say, from $u^{*}$ to $u$ in this case, simply reversing the order by which we arrived at utilitarianism's de facto $u^{*}$ in analyzing its maximized sum of $u$ 's.

Let's trace the steps. Suppose we are opportunityegalitarians, per Part II.C.3. We wish, then, to equalize the distribuendum discussed at Part II.A.3-material opportunity-over distribuees whom we take for boundedly responsible agents, per II.B.1. The latter are people who actively transform opportunities into welfare. In transforming their opportunities into welfare, these agents are in aggregate generating a form of global welfare. It is what we can call "equal-opportunity-grounded welfare."

The latter, then, is precisely what we seek to see maximized. Is it not? It is that maximandum which corresponds to what we take for the appropriate equalisandum. The only difference between this form of welfare and that of which utilitarians speak is that this form proceeds from antecedent conditions of equal opportunity and is produced in part by responsible agents. ${ }^{137}$ Utilitarian welfare, by contrast, is indifferent to the opportunity backdrop and to the responsible agency of distribuees. Its welfare aggregate is accordingly

137. The role played by the agents in generating the aggregate, in turn, suggests that our task as an operational matter is to equalize opportunity, leaving the transformation of that opportunity into welfare to the distribuees. "Leave the driving to us," the distribuees might say. See infra Part III, in connection with distribution mechanisms. 
differently generated, and is in that sense a different species of welfare aggregate. Process is partly constitutive of product, we might say. ${ }^{138}$

This all suggests that the formal renditions of utilitarian and opportunity-egalitarian norms can be rendered schematically identical, and are themselves structurally identical.

Where they differ is, first, in utilitarianism's calling $u^{*}$ the weighting assigned to individuals' exogenously endowed, birthconferred utility functions; while opportunity-egalitarianism calls $u^{*}$ the material opportunity afforded those same individuals. They differ, second, in utilitarianism's calling the $u$ whose sum over individuals is to be maximized "utility," a measure that is indifferent to individuals' agency, responsibility, or opportunity; while opportunity-egalitarianism calls that $u$ "equal-opportunity-grounded" welfare, a measure that is not thus indifferent.

The important point, then, is that both distribution formulae maximize something, both equalize something, and in both cases we can on pain of incoherence take the maximandum to be the right thing to maximize if and only if we take the equalisandum to be the right thing to equalize. It is worth noting a corollary while we are at it here: There is much unnecessary confusion in the theoretical literature concerning a putative distinction between the so-called "consequentialist" nature of maximizing imperatives on the one hand, and the "deontological" nature of fairness, or equalizing imperatives on the other. ${ }^{139}$ It even is claimed sometimes, surprisingly, that norms of the latter sort are inherently "ex post" in orientation, while those of the former sort are more "ex ante" in orientation. ${ }^{140}$ The ready interformulability of equalizing and maximizing formulae immediately suggests that this distinction is arbitrary. It is no more than an artifact of the symbolism we happen to employ.

138. The description under which the product in question is individuated, that is, includes essential reference to the generation-process. Process is "internal" to product in such case. See supra note 8.

139. See Kaplow \& Shavell, supra note 1, at 47-50 (observing that, despite their disregard for consequentialist outcomes, such notions of fairness may have broad appeal because of their "ex post perspective").

140. Id. 
This suggestion is borne out by the following consideration: "Deontology" refers simply to the logic, or structure, of duty. ${ }^{141}$ "Consequentialism" refers simply to the belief that consequences matter. All imperatives, whether cast in maximization or equalization terms, are laid down as duties. Functionaries are obligated to "Max" this or "Eq" that. ${ }^{142}$ The duties, in turn, speak to consequences. Utilitarianism lays down a duty to seek this consequence: a maximized aggregate that is the sum of equally weighted individual utility measures. Opportunity-egalitarianism lays down a schematically identical duty to seek this substantively alternative consequence: a fair distribution of material opportunity such as results in a maximized aggregate of equal-opportunitygrounded welfare. Both norms are as "consequentialist" as they are deontic; they simply articulate duties to seek different consequences. ${ }^{143}$

As for the putatively "ex post" orientation of "deontological" norms and "ex ante" orientation of "consequentialist" norms, it is difficult to know what to make of the claim. I doubt sense can be made of it. I note, though, that opportunity-egalitarianism speaks directly to the ex ante spread of opportunity, thereafter allowing the ex post equal-opportunity-grounded welfare aggregate to "take care of itself." It does so precisely because it is for agent distribuees to produce that aggregate out of the antecedent opportunity spread. Utilitarianism, by contrast, speaks directly to the ex post welfare aggregate, without regard for the ex ante spread of opportunity over responsible agents. Things look to be quite the reverse, then, of how they have been characterized, assuming I have managed to make sense of the characterization.

141. Id. at 42 .

142. Id. at 4 .

143. The term "consequentialism" as a name for utilitarian and cognate maximizing imperatives seems to have been introduced by Gertrude E. M. Anscombe. See Gertrude E. M. Anscombe, Modern Moral Philosophy, 33 Phil. 1, 12 (1958). Anscombe was, to be sure, a remarkably penetrating thinker. But it is tempting in hindsight to conclude that her singling out ethical systems by reference to their attention to consequences has ultimately led to more muddling mischief than salutary clarification. 


\section{DISTRIBUTION MECHANISMS}

I noted earlier that "to distribute" is subject to two forms of adverbial modification. One is by "ought" adverbs, which implicate distribution formulae as discussed just above. The other is by "can" adverbs, which implicate feasible distribution mechanisms, hence institutions and laws. We proceed now to the latter. Treatment of this subject receives a Part of its own because it is here, as we will see, that the more "purely" theoretic concerns of Part II find detailed application. In turning to distribution mechanisms we move from "Grundnorms" to specifically legal norms-the stuff of customs, treaties, statutes, regulations, and judicial decisions.

One might imagine many means by which to effect distributions of benefit and burden. Such means might be specified, in turn, at varying levels of abstraction. The possibilities here run from micro-detailed descriptions of existing institutions, on up to the quite broadly schematized designs contemplated in axiomatic mechanism theory. ${ }^{144}$ Surprisingly, most normatively oriented legal and policy analysts, domestic and international alike, have been quiet on the subject of feasible distribution mechanisms. That is regrettable for at least two reasons. For one thing, "can" limits "ought," as is commonly recognized. Hence "ought" claims that ignore "can" limitations risk being merely idle. And for another thing, some "can"s render some "ought"s particularly attractive. They do so not merely by rendering option menus more manageable via elimination of non-feasible alternatives, but also by highlighting ways we can sidestep even some theoretic conundrums, as I shall demonstrate.

One distribution mechanism that I shall specify appears to "fit" the most acceptable conceptions of distributor, distribuendum, distribuee, and distribution formula discussed above in Part II very gracefully and, as it happens, uniquely. That renders those

144. See, e.g., Louis J. Billera \& Robert E. Bixby, A Characterization of Pareto Surfaces, 41 Proc. Am. Math. Soc'y 261 (1973) (discussing the class of market games without transferable utility); Ehud Kalai \& Meir Smorodinsky, Other Solutions to Nash's Bargaining Problem, 43 Econometrica 513 (1975) (arguing, under four axioms that describe the behavior of the players, that there is a unique solution to the two-person bargaining problem). For an overview of axiomatic mechanism theory, pursuant to which institutions and markets are schematically characterized in abstract terms, see, e.g., Roger B. Meyerson, Mechanism Design, in The New Palgrave: Allocation, Information and Markets (John Eatwell et al. eds., 1989). 
conceptions more attractive on feasibility grounds, of course. But it also does more than that. The process of schematizing and justifying this mechanism further illuminates why those conceptions are independently attractive in the first place.

I will begin, then, by briefly characterizing the rough-hewn, composite mechanism-type that seems to be taken for granted as a background condition by most legal and policy analysts. It amounts to a vaguely specified mélange of decentralized market allocation, partly centralized private law rights-vindication by courts, and more centralized ad hoc intervention by legislatures and regulatory authorities. I will then briefly demonstrate a broad normative gulf running between this composite and the naïve maximization and prioritization theories discussed in Part II. Those theories, that is to say, are not equipped to underwrite specific prescriptions concerning what precise shape the composite should take.

I will then show that the opportunity-egalitarian ideal does recommend a particular, detailed configuration that the composite mechanism should take. Indeed, I maintain, this configuration seems even to constitute the institutional ideal toward which our more public good oriented legal, policy, and institutional designing is directed. The mechanism that is actually prescribed in detail by a Part II distributive ethic is an ideal toward which we appear to have been striving, with varying degrees of awareness, all along. I will call it the ideal of an "efficient, democratically regulated, endowmentneutral market."

\section{A. Mechanisms, Laws, Governments, Intergovernmental Organizations}

Most who speak normatively with respect to distributive questions take the following for granted: first, that most of the material things that matter to people-the "resources" or "material opportunities" of II.B above-are distributed by various forms of private bequest and exchange. Also, the latter presuppose already defined private law rights sounding in civil obligation-rights of property, contract, and tort-all recognized by courts of law. Finally, they take for granted that these rights are in turn subject to occasional amendment or alteration by centralized legislative action. Things seldom grow more fine-grained than this. ${ }^{145}$

145. For example, not one of the sources cited supra Part II describes or 
What ever the reasons for or causes of this want of detail, the consequences of mechanism-nonspecification are debilitating, both in terms of implementation and for the theory itself. For distributivetheory-building is, in its actuating ambition, institution-designing. Without imagining in some detail what the "outward expression" of prescriptive theory would look like, one remains unclear about what actually is being prescribed. It is as though one were attempting to think without language. Thought itself is left ill-formed and inchoate. ${ }^{146}$ We find this in all of the leading distributive-ethical theories currently on offer. What is missing in these theories comes to light most starkly when we ask what it would be to instantiate them. We can see this quite readily by briefly considering the best known such theories-those considered above in Part II under the previous distributive categories including distribuees, distribuenda, distribution formulae, etc.

\section{All Dressed Up and No Place to Go: Utilitarianism}

Consider first utilitarianism-i.e., naïve welfare maximization. Collecting the information assembled in Part II, we know that a utilitarian polity will wish to aggregate its patientdistribuees' unweighted welfare outputs and maximize the resultant sum. It will, moreover, be willing to do so "by any means necessary." For the utility aggregate is the sole normative touchstone guiding utilitarian policy, both as a matter of personal and of political morality.

But now consider: in view of the difficulties noted in II.C to afflict direct welfare-measurement, it is indeterminate what means would suffice or be necessary. If you cannot know when utility is maximized, can you know what to do in order to maximize it? Notwithstanding that inconvenient question, the utilitarian will regard a high degree of centralized government action as warranted

prescribes any distribution mechanism in more detail than just sketched.

146. Similar concerns animate Joseph Carens's and Robert Goodin's interesting work on institutional design. See Joseph H. Carens, Equality, Moral Incentives and the Market 3 (1981) (arguing that the conventional view of income inequality as inevitable relies on a limited set of assumptions about human motivation and politico-economic organization); Robert E. Goodin, Institutions \& Their Design, in The Theory of Institutional Design 34-37 (Robert E. Goodin ed., 1998) (discussing presuppositions underlying the connection between descriptive and prescriptive uses of design theory). 
and probably even required. For he will consider such authority to be necessary both for the regular collection of utility data and for the regular redistribution of holdings in order to maintain a maximal aggregate utility reading. And he will take the utilitarian planner to be unconstrained by any rights held antecedently by persons. ${ }^{147}$ The latter are utility-factories, not autonomous rights-bearing agents.

What is one to make of so dystopian and incoherent a picture? A government stunningly empowered in principle, but one that for theoretical reasons could not actually perform the function for which it was empowered: all dressed up and no place to go. In view of such difficulties as these, which are not merely implementary but foundational, utilitarianism looks to be a nonstarter where determinate distributive-ethical prescribing is concerned. It is prescriptively sterile or stillborn au fond, and its advocates, in leaving the mechanism variable unvalued, have served to conceal that fact.

\section{More Tastefully Dressed, Still No Destination: Rawlsian Justice}

Observations reminiscent of those made in connection with utilitarianism hold true when considering Rawlsian justice theory. Rawls himself was refreshingly candid about this. ${ }^{148} \mathrm{He}$ admitted that his concern was solely with what he called "the basic structure" of a just society. ${ }^{149}$ The problem, alas, is that the structure he seems to have had in mind is so basic that we do not know what Rawlsian principles have to say about matters such as a society's constitutional order itself, let alone subsequent legislation and private law doctrine. $^{150}$

147. The reason is that the utilitarian, as noted earlier, is concerned solely with maximizing the utility aggregate, and indeed assigns legal rights with that aim rather than fundamental rights in view. This is not even to mention redistribution's effects on effort-expense, hence goods and services production, hence the size of the utility aggregate itself. In view of utility's functioning as a fetish, incidentally, the need for an extensive governmental apparatus should not be surprising. In effect, the utility aggregate is a contemporary analogue to the pyramids of Egypt and the ziggurats of Mesopotamia and Mesoamerica. Societies organized around such monistic and inhuman pursuits have historically been both theocratic and autocratic.

148. Rawls, Theory of Justice, supra note 64, at 19-24.

149. Id. at 6 .

150. Id. at 176. 
Rawls left such matters for what he called later stages of polity-constituting, with which his work was said not to be immediately concerned. ${ }^{151}$ There seems to have been a rough expectation that there would be property rights and market exchange. ${ }^{152}$ But Rawls claimed his principles would be realizable in socialist societies as well. ${ }^{153} \mathrm{We}$ are accordingly left to wonder how Rawls's principles might so much as even begin to be operationalized. This raises a worry that the principles as articulated impart no determinate prescriptive information. Note further that this is a worry that already arose earlier, in connection with the indeterminacy of "the worst off class" in Rawls's prescribed distribution formula. ${ }^{154}$

Thus, Rawls's theory so underdetermines its own implementation that we do not know what to make of the theory itself-or, perhaps better put, what to make with it. How much is it actually telling us if it is equally realizable in any number of possible polities, each with radically divergent property, tort, contract, and other legal arrangements? Put differently, how do we recognize a Rawlsian society upon seeing one?

\section{Locally Determinate, Globally Indeterminate Prescription: Normative "Law \& Economics"}

Apart from the opportunity-egalitarian mechanism I will schematize below in Part III.B, the only serious mechanismproposals one finds in the distribution-concerned legal and policy literatures are those done by normative economists of law. ${ }^{155}$ Unlike utilitarians and Rawlsians, these analysts generally attend carefully to micro-institutional detail. They typically consider, for example, whether a property rule or a liability rule, or perhaps some particular default rule that forces a bargain, is apt to be wealthmaximizing in the long term. Yet by what might at first blush seem a curious irony, this is precisely their undoing from a distribution mechanism point of view. In the end there is less irony here than at first might appear, however. For the problem stems ultimately from a gap between macro-objective and micro-detail akin to that which I

151. Id. at $175-76$.

152. Id. at 239 .

153. Id.

154. See supra Part II.D.2.

155. That is, practitioners of normative "law and economics." 
have just noted in Rawls. ${ }^{156}$

The foundational mechanism problem for mainstream economics of law is rooted in a fallacy of composition: Suppose that each of $n$ rules $R a / 1, R a / 2, \ldots R a / n$ tends, within the confines of its particular domain $1,2, \ldots$ or $n$, to be wealth-maximizing in comparison to its envisaged competitors $b, c, d$, etc. in that domain. ${ }^{157}$ It does not follow from this that the full vector of rules $R a / 1 \ldots R a / n$ will be wealth-maximizing as compared, say, to some other vector $R b / 1 \ldots R b / n$ that would come to the theorist's mind only were he to contemplate a fuller institutional backdrop. The latter is a backdrop that is simply not on the agenda when all that is being asked is which of $R a / 1, R b / 1, \ldots R m / 1$ is wealth-maximizing in domain 1 considered in isolation. In effect, practitioners of normative economics of law consider domains one at a time, without reference to other domains or to interactions between domains.

But realistically speaking, choices in nominally distinct domains $1 \ldots n$ cannot reasonably be expected to be linearly independent. ${ }^{158}$ Rules within one domain will affect the distributive consequences wrought by rules in other domains. It would accordingly be dangerous to conclude from $R a / 1$ 's dominating $R b / 1$ in domain 1 , that the full vector $R a / 1 \ldots R a / n$ dominates $R b / 1 \ldots$ $R b / n$, let alone any other available vectors $R m / n$.

As this discussion shows, there is a gap in economics of law between wealth maximization on the macro level, and the evaluation of our rules and institutions on the micro level. This gap is "unbridgeable," because there is a "deep" foundational reason that

156. Rawls ignored micro in favor of macro, at macro's expense. Normative economics of law ignores macro, we will see, at micro's expense.

157. Think of a "particular domain" as, for example, the question of what kinds of damages should be available for a particular tort, or what rules should constitute the "consideration" regime in contract, or what should be required of pleadings in suits brought in fraud, etc. I designate such domains here with numerals-1, 2, 3, etc., on up to $n$. I am then designating alternative proposed rules within domains by lower case letters commencing with $a$. If 1 is the domain of contract remedies, then, and $a$ is specific performance, $b$ is liquidated damages, $c$ is compensatory damages, etc. in that domain, then the rules to that effect are here designated $R a / 1, R b / 1$, etc. Shift to another domain 2-e.g., remedies for battery-and lay out another menu of options $a, b, c$, etc., and there will be rules with names $R b / 1, R b / 2$, etc.

158. Indeed normative "law and economics," like much of the Marshallian/Pigouvian (as distinguished from Walrasian) welfare economics from which it descends, is confined to partial equilibrium modes of analysis. 
normative economists of law consider domains in isolation rather than in aggregate, a reason they cannot ignore without abandoning their enterprise altogether: the reason is that normative economics of law's guiding ideal-Kaldor-Hicksian "wealth-maximization"-is itself normatively indeterminate in macro. ${ }^{159}$ One simply cannot prescribe an initial distribution of entitlements on the basis of that distribution's ultimate effect upon total "wealth."

This is because "wealth" cannot be so defined until after an assignment of legal entitlements has already been carried out. This is not an empirical accident; it is a conceptual, definitional truth. There is no concept of "wealth" that is understandable apart from an antecedent distribution of entitlements. ${ }^{160}$ Hence there is no "wealth" aggregate to employ as a normative touchstone in deciding how best to distribute those entitlements. ${ }^{161}$ That means that normative economics of law cannot prescribe a macro-distribution of legal entitlements. ${ }^{162}$ It is, in the end, as prescriptively sterile as are utilitarianism and Rawlsianism.

159. For the seminal articles from which the pseudo-normative concept of Kaldor-Hicksian "wealth" derives, see Nicholas Kaldor, Welfare Propositions of Economics and Interpersonal Comparisons of Utility, 49 Econ. J. 549 (1939) (arguing that an economist need not prove that no one will be worse off as the result of a given policy to show that the policy is efficient); John R. Hicks, Foundations of Welfare Economics, 49 Econ. J. 696 (1939) (arguing that a proposed policy cannot be judged to maximize social welfare without taking account of the policy's negative effects). An explanation of Kaldor-Hicksian wealth is provided by Posner in the first edition of his Economic Analysis of Law. See Richard Posner, Economic Analysis of Law 213-22 (1973) (stating that wealth is that which is maximized when all goods are in the possession of those who most value them).

160. The matter is ably treated in Coleman, supra note 85.

161. This is, in effect, a manifestation of the "Scitovsky Paradox"-the possibility for two states of the world to be Kaldor-Hicks superior to one another. See Scitovsky, supra note 85 and accompanying text. Note that utility, were it measurable, would not be vulnerable on this score, even though it would be fetishist for reasons provided supra Part II.C.

162. Posner, to his credit, accepted criticism to this effect early on. He then claimed that the problem did not afflict what I am here calling the "micro" choice problem of selecting between possible rules within a single, more limited domain. But that is precisely what I am claiming here to be the problem for normative economics of law from a mechanism-prescriptive point of view. If the macro backdrop must be normatively evaluated, and such a task is literally impossible using normative theory, one's micro-critiques have not been made normatively intelligible. 
This fact is masked solely by restricting normative economics of law to micro-distributions. Our attentions are thus deflected away from the macro-distribution, and from the fact that normative economics of law is conceptually incapable of evaluating that distribution. And where macro-evaluation is impossible, microevaluations lack ultimate normative content. They are in consequence normatively uninteresting.

The reason is that they are conducted by reference to a normatively arbitrary aggregate-the special form of "wealth" invented by normative economics of law itself. That aggregate is normatively arbitrary because it is produced against a normatively arbitrary backdrop-i.e., on the basis of a distribution of entitlements which, as previously discussed, economics of law simply lacks the conceptual resources to evaluate and make recommendations about. The "wealth" of normative economics of law is accordingly no more ethically interesting than, say, the aggregate of "forehead height" countenanced above. ${ }^{163}$

Yet again, then, insufficient attention paid to the unseverable nature of practical distribution mechanisms with the "purely theoretical" results in a gaping blind-spot. We fail to notice that certain would-be distributive prescriptions are not merely difficult to implement, but in fact misfire at the stage of prescription itself. We get nowhere-we do not even point anywhere-until we work completely to specify valuations of all of the variables opened by distributive infinitives at once.

\section{B. One Satisfactory Mechanism}

The previous subsection might seem to underwrite pessimism. One might fear, given the failings of normative distributional theories thus far, that the problem is simply intractable. But fear not. There is a mechanism that determinately realizes the best vector of values proffered in Part II to fill the distributive variables. Intriguingly, moreover, this fact does not seem to be mere happy accident: analyzing this mechanism's ability to vindicate the values discussed supra, also shows the independent attractiveness of the values themselves. That is an attraction additional to the practical advantages offered by this mechanism's capacity to realize the best valuations. What is more, I shall indicate,

163. See supra note 16. 
our laws, policies, and institutions appear to be animated, at least in part, by a shared societal commitment to realizing precisely this mechanism.

\section{One Fully Specifiable Mechanism: Real Opportunity-Spreading}

To envision the mechanism I have in mind, begin by assuming a "complete" market. That is a forum in which all and only desired, voluntary trading occurs. ${ }^{164}$ Assume that this trading is in, first, all goods and services that can practically be made available and that anyone values. These would be, in the terms of Part II.C above, all things that are intelligible as normatively interesting distribuenda. ${ }^{165}$ Assume that the trading is in, second, "Arrow securities." 166 These are contingent claims to compensation upon the occurrence of certain events that distribuees might disvalue. The

164. Market "completeness" in this sense includes trading in contingent claims, which I will discuss in the next several paragraphs. I will also argue that completeness in this sense is a function, in part, of what I shall presently label "neutrality," a fact which appears to go largely ignored. For the classic sources on the role of contingent claims in completing markets, see John R. Hicks, Value and Capital 2 (1940) (comprising the study of the interrelations and mutual interactions of markets); see also Gerard Debreu, Theory of Value 28-103 (1954) (explaining how prices and commodities are affected by private agents of free markets); Maurice Allais, Généralisation des Théories de L'Equilibre Economique Général et du Rendement Global au Cas du Risque, 11 Econometrie, Colloques Internationaux du Centre National de la Recherche Scientifique 81 (1953); Kenneth J. Arrow, The Role of Securities in the Optimal Allocation of Riskbearing, 31 Rev. Econ. Stud. 91, 91-96 (1964) (discussing the effect of riskbearing on markets and securities). Completeness is more precisely characterized by formal means. Its presence bears many ramifications, only some of which can be treated here. For more complete treatment, see Robert Hockett, Just Insurance Through Global Macro-Hedging, 25 U. Pa. J. Int'l. Econ. L. 107, 114 (2004) (assessing the systemic and social roles of risk and insurance in a new global economy); see also Michael Magill \& Martine Quinzii, 1 Theory of Incomplete Markets 1 (1996) (developing an equilibrium model for how agents deal with imperfections and uncertainties in markets).

165. Assume also, for obvious reasons, that valued "goods" and "services" do not include among them the nonconsensual expropriation of others' entitlements, which would violate the neutrality conditions that I describe later. I will also explain how to apportion and determine entitlements, and that which counts as expropriation.

166. The term has entered common welfare economics language as a result of its origin in Arrow, supra note 164. See generally Hockett, Just Insurance Through Global Macro-Hedging, supra note 164. 
compensation is payable by anyone willing to take the opposite side of what amount to "bets" on the disvalued contingencies. ${ }^{167}$ In effect, then, they are "mini-insurance policies."

Assume next that the market I describe also is "neutral." Each participant enters it with an initial endowment of ethically exogenous assets, the "material opportunities" of Part II.C.2, which are equal in value to that with which everyone else enters it. Call this form of neutrality entry neutrality.

The market I have in mind also is neutral in a second sense. Regulatory norms prevent such strategically opportunistic behavior as can yield a particular consequence. Market participants may not come to possess greater or lesser holdings, or price-affecting demand powers, than those traceable to (a) the participants' ethically exogenous initial endowments, and (b) their ethically endogenous, or responsible, transaction histories. Call this form of neutrality process neutrality. ${ }^{168}$ It is the sort of neutrality that Europe's "competition law," and America's "antitrust law," are each meant to maintain.

This mechanism straight-forwardly instantiates a particular set of valuations of the distributive variables discussed above at Parts II.A through II.D. It also, simultaneously, sidesteps the three critical measurement concerns discussed at Part II.C, in a manner that no other mechanism so much as begins to attempt.

First, I will discuss this system's valuations of the distributive variables. Note first that the mechanism honors distribuees as boundedly responsible agents, as characterized above in Part II.B.1. Distribuees transact voluntarily pursuant to their own, autonomous relative valuations of material goods, ills, and contingencies that they prefer and disprefer. What they hold or enjoy at any given moment is, moreover, a function of those same autonomous valuational and transacting decisions.

Note next that the mechanism treats as distribuenda whatever non-neutrality-violative goods or services, including riskbearing services, the agent-distribuees themselves value or disvalue.

167. See Robert Hockett, Gaming as Micro-Insurance: How and Why to Regulate, not Eliminate, Online Gambling (unpublished manuscript, on file with the author).

168. Please set aside, just for the moment, the questions of means by which endowments would be measured and endowment-equalization effected. We will get to those shortly. 
These goods and services are the resources or material opportunities countenanced above in II.C. 2 and II.C.3. They are that from which, in conjunction with their choices, distribuees derive welfare.

Note finally that the mechanism, via the entry neutrality imposed upon it at the outset and the process neutrality retained throughout, equalizes what is ethically exogenous, or that which is not traceable in the holding directly to a responsible choice. At the same time, it allows holdings over time to vary with ethically endogenous, or responsible, transactional and other decisions. The distribution formula to which the mechanism gives expression, then, is the opportunity-egalitarian formula characterized above in Part II.D.3.

As we proceed to measurement challenges, note first that the mechanism sidesteps the problem of cardinal welfare measurement discussed at II.C.1. It does so by enabling agent-distribuees, via their voluntary trading activity, to maximize welfare in a manner consistent with two conceptually equivalent, normatively required conditions: (1) ethically exogenous endowment equality among market participants, per the opportunity-egalitarian requirement characterized in Part II.D.3; and (2) an equally shared scarcity of the exogenously given resources from which agents "produce" their own welfare. ${ }^{169}$ Note that the maximization of this normatively intelligible

169. In essence, we are describing an economy characterized by so-called "equal division Walrasian equilibria," or "EDWEs." The technical literature on the theory of EDWEs and fair allocation more generally is vast, though curiously ignored by economically-oriented legal academics. For a canonical sampling, see Terrence E. Daniel, A Revised Concept of Distributional Equity, 11 J. Econ. Theory 94 (1975) (developing a concept of equity as a measure of the distributional equity of allocations in private goods economies with production); Duncan Foley, Resource Allocation and the Public Sector, 7 Yale Econ. Essays 45, 45-98 (1967); Elisha A. Pazner \& David Schmeidler, Egalitarian-Equivalent Allocations: A New Concept of Economic Equity, 92 Q.J. Econ. 1, 1 (1978) (attempting to define economic justice through numerical and mathematical terms); Elisha A. Pazner \& David Schmeidler, A Difficulty in the Concept of Fairness, 41 Rev, of Econ. Stud. 441, 441-43 (1974) (raising a new difficulty concerning the possibility of satisfying Pareto efficiency and equity goals simultaneously); Hal R. Varian, Equity, Envy and Efficiency, 9 J. Econ. Theory 63, 63-91 (1974); Hal R. Varian, Two Problems in the Theory of Fairness, 5 J. Pub. Econ. 249 (1976) (evaluating equity and fairness in a pure exchange economy). The work from which these studies depart is Leon Walras, Elements of Pure Economics (William Jaffé trans., 1954) (1844) (providing an assessment of the balance of social, psychological, and economic incentives in industry). Walras appears to have anticipated, indeed even inchoately to have intended, precisely 
form of welfare ${ }^{170}$ is effectively "guaranteed" to occur: That is a straight-forward entailment, in the present context, of the "first fundamental theorem of welfare economics. ${ }^{171}$

Now note that, similarly, the mechanism unobjectionably sidesteps the problem of interpersonal welfare comparison discussed at Part II.C.1. So long as the material opportunity components of welfare-manufacture ${ }^{172}$ are counted ${ }^{173}$ among the exogenous endowments that must be equalized over participants, the following will hold true: Whatever the absolute or comparative quanta of welfare enjoyed by distribuees, these will be the "highest" that they can be (as consistent with Part II.D.3's opportunity-egalitarian distribution formula and the resulting equally-shouldered constraints posed by the environment).

Finally, the mechanism "automatically" commensurates distribuenda, per the discussion of Part II.C.2, in the only way that ethically matters, via the implicit comparative valuations of autonomously transacting agent-distribuees. ${ }^{174}$ We need not concern ourselves with how much of some good G2 "would" or "will" compensate person $P 1$ for a deficit of good $G 1$, let alone seek to construct a "perfectionist" index of all such goods and ills. ${ }^{175}$ Our distribuees themselves will, in effect, autonomously and with equal

such developments in addressing interests of efficiency and equity. See Willam Jaffé's Essays on Walras 326-42 (Donald A. Walker ed., 1983) (showing Walras's desire to define social justice and social utility through economics and mathematical equations).

170. For a reminder of the contrasting, normatively unintelligible form of welfare, see supra Introduction and Part II.C.1.

171. See Kenneth J. Arrow, An Extension of the Basic Theorems of Classical Welfare Economics, in Proceedings of the Second Berkeley Symposium on Mathematical Statistics and Probability 507, 507 (1951).

172. These material opportunity components include physiological determinants.

173. For example, in the form of drugs, prostheses, or contingent claims to those and other forms of compensation to equalize material opportunity.

174. See Hockett \& Risse, supra note 64.

175. Id. The claim that the need to index commits one to perfectionismthe proposition that some goods are inherently more worthy of collective pursuit than others-figures into a prominent criticism of Rawlsian primary goods leveled by Arneson. See Arneson, supra note 113, at 445-46 (1990) (arguing that there really is no alternative to subjectivist standards of distributive justice that let the valuation of resource shares depend on the evaluation that each individual herself gives to her share). The criticism is addressed in Hockett \& Risse, supra note 64 . 
voice construct the only normatively salient index, which is, in effect, a spontaneously emergent price index. And so long as entry and process neutrality are maintained, this latter amounts to the ethically relevant "global" valuation of goods and ills. That is a valuation in which each participant has exercised an equal "vote." Prices, then, in a market bearing the "completeness" and "neutrality" attributes discussed above, will be what the Medievals long sought but never found-“just prices."

\section{Instantiability-Challenges and Ordered "Nth Bests"}

The opportunity-egalitarian market mechanism, then, insofar as it can be instantiated, simultaneously assists in realizing what looks to be the most plausible vector of Part II distributive values while also meeting or neutralizing each of the principal measurement challenges. Moreover, the ways in which it does so serve to reinforce the values discussed in Part II, including distributors and distribuees as boundedly responsible agents, distribuenda as material opportunities, and distribution formulae as opportunity-egalitarian.

Three obstacles might seem to stand in the way of the mechanism's realization. Dispatching them will be necessary if we are to be confident that opportunity-egalitarianism is any more practicable, or even prescriptively determinate, than its competitors addressed in III.A. The process of addressing the challenges, however, ends up affording affirmative advantages as well. For in addressing them we come to notice that the mechanism actually amounts to a normative refinement and completion of the mechanism specified by the economics of law. In addition, we will learn that the mechanism is progressively instantiable over time, in a manner that ordinally replicates a normative scale from " $n$th best" to "first best." We find that our laws, policies, and institutions appear to be actuated by the implicitly shared goal of ascending that scale. ${ }^{177}$ And

176. Again, provided that there exist market completeness and neutrality in the senses explicated above. Trading here is voting, and voting rights are equally spread in the only sense that ethically matters: equal bargaining power involving the apposite form of equality, viz., equality of ethically exogenous endowments.

177. Hence, we will see reason to displace even "positive" economics of law with a more convincing picture. 
finally, we realize that there are means by which to more fully realize the mechanism that we are not yet employing.

I will specify and then address each of the challenges in serial order. I will note the aforementioned "fringe benefits" that addressing these challenges produces as they are implicated.

The first challenge arises in connection with marketneutrality, and in particular with entry-neutrality. If we are to equalize holdings of the material opportunity endowments with which agent-distribuees enter the market, we must presumably commensurate those endowments. But how are we to do that prior to the operation of the market mechanism when it is the market itself that affords the ethically satisfactory method of commensuration? Is there not a pragmatic indeterminacy at work that is just as vitiating as the indeterminacies of utilitarianism, Rawlsian justice theory, and normative economics of law?

The answer is no. To show why not, we proceed in three steps. First, we demarcate certain classes of material opportunity endowment that are unambiguously ethically exogenous in the holding. We will call these "core endowments." Second, we indicate the means by which the holding of those core endowments can be readily equalized. Finally, we show that any forward movement in these directions is unambiguous movement toward the ethically optimal distribution. The ideal mechanism is straightforwardly approached in a continuously upward-sloped fashion.

First, then, we must address the core endowments. At least four classes of endowment are uncontroversially ethically exogenous in the holding, the most obvious being the genetic determinants of successful welfare-pursuit. Just as many handicaps are obvious and incontestably undeserved, many talents are likewise incontestably unearned. The advance of empirical science enables us to grow ever more able to sort out, at least probabilistically, what is predisposed and what is not. The second includes both childhood healthcare and education. Children do not earn or deserve greater or lesser access to such assets, particularly when they are very young. Their degrees of responsibility gradually grow as they move toward adulthood. The third category encompasses inherited nonhuman capital, or moneyvalued wealth. Like other forms of inheritance, this one is morally arbitrary, and it does not grow less so with time and maturation. Finally, the fourth class includes opportunity to shed or share unforeseeable risk through trade or collective risk-pooling action. 
This is best seen as non-confiscatory compensation for deficits in other resources or material opportunities. ${ }^{178}$

Core endowments of these types not only are manageable in number, but with the advance of empirical science are also growing more readily quantifiable, directly allocable, and indeed allocable equitably. They are also in little, if any, need of commensuration inter se. Moreover, if we distinguish between beneficial and burdensome endowments we see that this is particularly so of the beneficial ones: early education, healthcare, and inherited nonhuman capital. The burdensome endowments are somewhat more difficult, since they disproportionately include physiological resources. But they, too, are far from unmanageable.

The hardest of the latter is genetically poor health or handicap. Some such deficiencies can be valued by reference to current prices affixed to their mitigation- prostheses, or medicines. There seems to be no harm in beginning to address such deficits with compensation equal to the going rates. Other such deficits are not so readily mitigated. With those deficits, the best that we can do is to estimate the compensation afforded by insurance policies that typically are, or perhaps "would," be purchased against such contingencies were they available. ${ }^{179}$

178. Some seek to include the presence of counter-traders in the opportunity set here. See, e.g., Colin M. MacCleod, Liberalism, Justice, and Markets: A Critique of Liberal Equality 13-16 (1998) (arguing that society must have a non-market account of the "circumstances of authenticity," or the social conditions under which we form preferences and beliefs about the good, before determining the proper role of the market, and that society should be more aware of the many ways in which real world markets fall short of meeting the demands of justice); Markovits, supra note 36. I think this position is mistaken-in effect, a retreat from the position from which one treats distribuees as responsible agents-by dint of its treating co-persons and their responsible tastes as resources. I count only infrastructure.

179. See Hockett, Whose Ownership, supra note 123, at 217-37; Dworkin, supra note 36 , at 307-50. Real, rather than "hypothetical," such insurance is proposed in Hockett, Just Insurance, supra note 164; Alexander Tabarrok, Trumping the Genetic Tarot Card, 9 Contingencies 20 (1997) (exploring the possibility of "genetic insurance" to insure against possessing "bad" genes, which, if possessed, would allow for provision of compensation); see also John $\mathrm{H}$. Cochrane, Time-Consistent Health Insurance, 103 J. Pol. Econ. 445, 446-50 (1995) (proposing a system of time-consistent insurance contracts that use severance payments to insure people from overly expensive health care or denial of coverage due to long-term illnesses). 
Clearly there is some guesswork here, but it need not be whistling in the dark. With the growth of empirical knowledge we grow better at estimating with greater reliability. We do what we can to repair the ship at sea, if I may borrow Neurath's old simile. ${ }^{180}$ The more such repairing we do, the more capable the mechanism grows at improving itself.

The first challenge to mechanism-instantiability, as we saw above, concerns neutrality, but the second concerns completeness. It asks: Is it reasonable to require that "all and only desired trading" occur? Is that possible, and should we even wish it? Would not we have to abandon our market-inalienability norms and "commodify" everything? ${ }^{181}$ And if we do not do that, can the opportunityegalitarian market mechanism that I have described discharge the tasks I have assigned it?

This challenge is more easily addressed than that directed to neutrality. To begin with, consider the core opportunity endowments again. Each of these is already subject, in principle, to unobjectionable market-valuability. We have already "commodified" what most needs commodifying here.

Next consider what else might be traded, which includes all that enters into responsible agent-distribuees' welfare-pursuits. It is easy enough simply to bracket out of market transactions such things, which, in our estimation, should not be commodified-babies, blood, or human organs, for example-and still approximate to

180. For Neurath's simile, see 2 Otto Neurath, Gesammelte ökonomische, soziologische und sozialpolitische Schriften 215-16 (R. Haller et al. eds., 1988).

181. For the classic contemporary objection to "commodification," see Margaret Jane Radin, Market-Inalienability, 100 Harv. L. Rev. 1849, 1849-52 (1987) (exploring the significance of market-inalienability and its justifications, and offering her own theory that relates it to an ideal of human flourishing); see also Michael Sandel, Public Philosophy (2005) (arguing that individual rights and freedom of choice do not by themselves provide an adequate ethic for a democratic society but rather must be joined with a politics of citizenship, community and civic virtue). Contemporary protests of commodification revive concerns raised repeatedly in the past. For two classic Victorian-era objections, see Thomas Carlyle, Past and Present (Robert Thorne ed., 1890) (contrasting the life of his contemporaries, driven by impersonal economic forces and abstract theories of human "rights" and natural "laws" with the lives of medieval abbots whose monastic communities were unified by human and spiritual values); John Ruskin, Unto This Last and Other Writings 155-228 (Clive Wilmer ed., 1985) (attacking laissez-faire capitalism to propose a theory of political economy which provides moral constraints on wealth accumulation). 
distributing goods and services as best permitted. For again, as I will show, there are "second" down to " $n$th best" distributive arrangements, ordered equivalently to degrees of neutrality and completeness. ${ }^{182}$

That is the desirability side of the "completeness" challenge. The feasibility question asks the following: Is it reasonable to suppose that all parcelings of ownable and tradable goods, and that payment-claims defined in terms of all specifiable contingencies, might be made tradable? Can we really "complete" markets in the sense one would require? ${ }^{183}$ Here the problem, the guise of which is more technical than the alienability guise, can be handled in three ways.

The first way is to note that it is by now a well-established theorem of general equilibrium-and stochastic calculus-rooted financial theory - that complete markets can be simulated through a comparatively small number of hedging strategies. ${ }^{184}$ Moreover, the number of contingent claims that can be made tradable is growing almost by the day. I exploit those facts elsewhere. ${ }^{185}$ So we can do a lot more completing than we have done thus far.

The second and third ways of addressing the completeness challenge are more immediately satisfying. For one thing, greater entry-neutrality itself yields greater completeness. This is so because

182. See Elisabeth M. Landes \& Richard Posner, The Economics of the Baby Shortage, 7 J. Legal Stud. 323 (1978) (analyzing whether the regulation of baby selling is economically sound, and exploring alternatives as to how a market in babies would function). The blood and human organ allusion is to the wellknown Titmuss example. See Richard Titmuss, The Gift Relationship: From Human Blood to Global Policy (1970) (postulating that altruistic behavior can account for the greater prevalence of blood donation in Britain than in the United States).

183. Thank you to Henry Hansmann for first pressing me on this score.

184. See Robert C. Merton, Lifetime Portfolio Selection Under Uncertainty: The Continuous-Time Case, 51 Rev. Econ. \& Stat. 247, 247 (1969); Robert C. Merton, Optimum Consumption and Portfolio Rules in a Continuous-Time Model, 3 J. Econ. Theory 373, 373 (1971); Robert C. Merton, Continuous-Time Portfolio Theory and the Pricing of Contingent Claims (Sloan School of Management, MIT, Paper No. 881-76, 1976).

185. See Hockett, Just Insurance, supra note 164, at 114-15; Robert Hockett, What Kinds of Stock-Ownership Plans Should There Be? Of ESOPs, Other SOPs, and "Ownership Societies," 92 Cornell L. Rev. 865, 945 (2007) (describing how American ownership of business stocks can, and should be, as widespread as homeownership). 
completeness rides, in part, upon all desired trading being available. Furthermore, more trades per unit of wealth occur at lower levels along personal wealth curves. Lastly, entry neutrality accordingly opens market doors to larger numbers of participants who enter at the low end. Hence greater entry neutrality results in more trade.

For another thing, the completeness-feasibility problem has no more than an illusory "bite" here. For, as my answer to the third, and final, challenge will show, more complete and more neutral always means more consistent with an opportunity-egalitarian allocation: There is an ordered set of " $n$th bests" that is equivalent to the set of "more" complete and "more" neutral markets. Let me, then, turn to the third challenge.

Suppose you cannot achieve full completeness and neutrality of the sort that characterizes the ideal mechanism. In that case, might you not in seeking merely more completeness and neutrality than you presently have, ironically end up farther from your ideal end-state? Has not Hart, for example, proved that the move from less to more complete markets short of full completeness can incur Pareto-losses? ${ }^{186}$

The suggestion, then, is that ascending degrees of completeness and neutrality might not be ordinally equivalent to a scale of $n$th bests. The suggestion happens to be false. The intuitive reply is that the suggestion turns crucially on a normatively uninteresting conception of efficiency. Indeed it turns on the Pareto and Rawlsian theories that we have already found, in effect, to be ethically noncognizable above at Parts II.D.1 and III.A.3.

"Efficiency," in the everyday sense of the word, connotes the maximization of output given a stipulated input, or the minimization of input given a stipulated output. It means roughly "more for the same" or "the same for less." The more technical understandings of "efficiency" familiar to welfare economists and normative economists of law amount to variations on that theme.

Pareto-efficient distributions of goods or ills to persons are best understood, intuitively, as distributions where the derived

186. See Oliver D. Hart, On the Optimality of Equilibrium When the Market Structure is Incomplete, 11 J. Econ. Theory 418, 431 (1975) (arguing that "[i]f the economy contains more than one good or lasts for more than two periods, then an equilibrium generally will not even be Pareto optimal relative to the set of competitive equilibria $\square^{\prime \prime}$ ). 
quasi-aggregated preference-satisfactions cannot be raised without lowering the individual preference of at least one person. ${ }^{187}$ That is the sense in which it amounts to a form of "efficiency," the one sense in which it can warrant the use of that word. Pareto efficiency is the maximization of aggregate preference-satisfaction as constrained by a polity-conferred "veto." ${ }^{28}$ In this case the veto is that wielded by any distribuee-including a thief, per the discussion in Part II.C.1who stands to suffer a satisfaction loss in consequence of some social restriction.

Kaldor-Hicks efficiency is yet closer to the workaday understanding of "efficiency." The reason is that it is unapologetically aggregative rather than quasi-aggregative. Distributions are efficient in the Kaldor-Hicks sense if there is no departure from them that would render some parties' aggregated gains greater than other parties' aggregated losses. ${ }^{189}$ The guiding intuition, then, again, is that the scalar welfare output of a given wealth-distributive input vector is, given the individual welfare functions (input vector components) that we have to work with, the "highest" it can be. ${ }^{190}$

But now consider what this means. It means that Pareto and Kaldor-Hicks efficiency alike are forms of "naïve maximization," in the parlance of Part II.D.1. They are in consequence normatively inert. Their maximanda-distributive-ethically unfiltered preference satisfaction in the one case, and opportunity-indifferent "wealth" in the other-are ethically irrelevant magnitudes. They are no better than, say, forehead height.

Efficiency on either the Paretian or the Kaldor-Hicksian scale, then, is devoid of normative interest. For the only form of welfare that matters is what we called in Part II.D "equalopportunity-grounded welfare." The only form of efficiency that matters, accordingly, is the form that maximizes this form of welfare. And the maximization of this form of welfare, as we saw in Part II.D.3, "takes care of itself" as we work to equalize the distribuendum that is material opportunity over the distribuees who are boundedly

187. See generally Hockett, supra note 13.

188. Id.

189. See Kaldor supra note 159; see also Hicks supra note 159.

190. One "produces" welfare, in the Pareto and the Kaldor-Hicks senses, by distribution operations. Those are the variable inputs, so to speak, while persons' utility functions are the fixed inputs. 
responsible agents. ${ }^{191}$ Because it is normatively uninteresting, the third challenge facing the opportunity-egalitarian market mechanism simply evaporates. ${ }^{192}$

\section{The Role of Law}

Among the advantages offered by reflecting upon how to instantiate that distribution mechanism which gives best expression to the most plausible distributive ethic is the following: we notice in doing so that the laws, policies, and institutions typically encountered in the advanced political-economies seem intended in large part to foster and buttress some such mechanism as that which I have just sketched and defended. ${ }^{193}$ Thinking along the lines of Parts III.B.1 and III.B.2 above, then, offers further advantages.

First, it will enable us better to interpret our own legal traditions, and thus to extend the tradition in a manner more in keeping with its own animating ideals. Relatedly, it will position us to improve the laws, policies, and institutions that we have, with a view to rendering the resultant mechanism both more complete and more neutral, hence more fully in keeping with its own opportunityegalitarian ideal. And third, by way of theoretic side-benefit, it will better enable us to see what mainline economics of law has right and has wrong, and thus fashion that discipline in a more effective manner. Let me, then, at least preliminarily bear out the interpretive claim.

Much familiar private law doctrine across modern jurisdictions seems to be transparently opportunity-egalitarian, emphasizing individual responsibility. Consider, for example, the

191. Recall that the opportunity-egalitarian distribution formula laid out in Part II.D.3 requires not only that ethically exogenous holdings of that from which ethically endogenous wealth and welfare are derived-material opportunity, "R $i$ "--be equalized; it also requires that ethically endogenous such holdings - " $E i$ " - be left to vary with the responsible choices that produce them.

192. The third challenge should not be confused with another possible challenge-that some means of affording more completeness or neutrality in one sphere of activity might lessen the degree of completeness or neutrality in another. To what extent such interactions occur is an empirical question, not one of "high theory." I will address this question below in connection with the matter of comparative institutional competencies.

193. We might say, then, that early normative economics of law was positively incorrect in a manner precisely analogous to that in which it was normatively incorrect. 
concept of "diligence" across property, contract, and tort in common law, civil law, and modern "hybrid" legal traditions. Likewise, the concept of adverse possession in most property regimes, mitigation of damages in most contract regimes, and comparative negligence in most tort regimes, emphasizes accountability. Even the presumption in favor of contractual freedom found in most modern legal systems seems rooted in respect for autonomy, or responsible agency.

In remedies, concern for "making the plaintiff whole" per the compensatory damages regime looks straight-forwardly actuated by considerations of corrective justice: it is a matter of equalizing present circumstances to a status quo ante. And the many doctrines of equity jurisprudence that pervade our law are of course transparently exogenous circumstance equalizing and responsibility vindicating in nature, as both the term "equity" and its ThomistAristotelian roots would have led one to anticipate.

Public law, too, is best viewed as an attempt to afford something like greater neutrality and completeness of the sorts I have assayed just above. Laws prohibiting invidious discrimination on the basis of racial, gender, and other ineluctable or morally arbitrary traits, for example, look to be straightforward cases of process-neutrality-promotion. Public education and sundry forms of government-facilitated global insurance for their parts are aimed at promoting entry-neutrality. They work to equalize ethically exogenous material opportunity endowments- the "Ri" of Part II.D.3. Moreover, such neutrality-boosting measures, for reasons noted earlier, tend to enhance market completeness as well.

There are other completeness-enhancing measures that advanced political economies have taken steadily over the past decades and even centuries. The trend with respect to "commodification," for example, seems by and large to have been to permit, and indeed in many cases even to foster, the trading of more and more goods and services, including contingent claims. Witness government encouragement of secondary debt "securitization" markets in the United States since the 1930s, for example, as well as its funding much research that has led to the design of derivative securities. ${ }^{194}$

194. See, e.g., Hockett, Just Insurance, supra note 164; see also Hockett, $A$ Jeffersonian Republic by Hamiltonian Means, supra note 123. 
The "commodification" trend has led to "unbundling" more and more once-conjoined items into separately traded items. ${ }^{195}$ Conspicuous cases of such market-fostering include government regulatory and start-up support for active markets in securities, derivatives, and more recently, pollution rights trading. ${ }^{196}$ Conspicuous cases of mandated unbundling, which incidentally show again the linkage between neutrality and completeness, include antitrust action against large telecommunications concerns in the $1980 \mathrm{~s}$ and software manufacturers in the $1990 \mathrm{~s} .{ }^{197}$

The fact that such measures can often be argued to enhance aggregate global welfare, as well as wealth or consumer surplus, should not surprise us. Nor should it be taken for unalloyed indication that legislatures or common law judges do, let alone ought, to craft law, doctrine, or policy with a view to maximization alone. All the less should it be taken for encouragement to conceive "improvements" we think likely more fully to effect aims of that sort. For we have seen now that opportunity-indifferent aggregatemaximizing is normatively empty. And we have seen that equalopportunity-grounded maximizing nevertheless overlaps in part, short of full coextension, with other forms of maximizing. ${ }^{198}$

That fact itself explains how "positive" economists of law in the past were able to suppose common law judges subconsciously actuated by Kaldor-Hicksian wealth-maximizing aims. We would effectively fine-tune mainline economics of law, then, by interpreting our legal arrangements as effectuating the responsible agency, equal opportunity ideal. We should, in turn, frame our own efforts at improvement of our laws and institutions in keeping with the same objective.

If I am correct in what I suggest here, then a substantial new research agenda is opened for what might be called an "ethically intelligible economics of law." Some actual or proposed rules thought to be wealth-maximizing, for example, will prove suboptimal in light of the opportunity-egalitarian ideal. Responsive amendments to such

195. See, e.g., Magill \& Quinzii, supra note 164 .

196. Id.

197. See, e.g., Steve Lohr, U.S. versus Microsoft: The Horizon, N.Y. Times, Nov. 11, 1999, at A1; Leslie Wayne, A.T. \& T.'s New Challenges, N.Y. Times, Feb. 4,1982 , at D1.

198. Recall that EDWEs, for example, happen also to be Pareto-efficient, as observed supra note 169 and accompanying text. 
rules might carry us towards realizing the ideal mechanism I have schematized. Parallel remarks of course hold true of our efforts to interpret and extend the rules that we have, as well as to formulate, legislate, and administratively implement the best new policies and programs possible.

\section{Comparative Legal \& Institutional Competencies}

I should, in closing this discussion of distribution mechanisms, perhaps say a few words about what I am not claiming. Certainly I do not mean to suggest that domestic or world courts should attempt to make general determinations of litigants' overall material opportunity allotments in deciding cases. Even less do I mean to imply that they should allow such determinations to enter into decisions as to who should prevail in litigated cases, as if courts were engines of non-case-specific compensation or distribution. Nor do I intend here to recommend that legislators, policy-makers, or treaty-negotiators as a general rule prescribe that persons who fare unjustifiably poorly in one sphere of activity be held to different standards in other spheres of activity, in order that they may be compensated overall.

My gut intuition, which I take to be widely shared, ${ }^{199}$ runs in the other direction. It is that the integrity and longterm stability of institutions operating in the many different "spheres" of activity that jointly constitute a pluralist global society require we not typically determine individuals' outcomes in one sphere by reference to their outcomes in other spheres. ${ }^{200}$ Hence my intuition is that full opportunity-equality among persons requires our working severally-but simultaneously-toward opportunity-equality sphere

199. Indeed, I take the intuition to be broadly Toquevillean, and perhaps in that sense particularly "American."

200. See, e.g., Jon Elster, Local Justice 133 (1993) (stating that "[t]here is no mechanism for redress across allocative spheres]"); Alistair McIntyre, After Virtue 253 (1979) (discussing the Supreme Court's preference for fairness by even-handedness in the Bakke case); David Miller, Principles of Social Justice 78 (1999) ("Thus, the claims of need will always be vulnerable to challenge by the claims of desert once we move outside a small-group context."); Michael Walzer, Spheres of Justice 10 (1983) (arguing that, though there is no single standard against which all distributions are measured, there is a relative autonomy among different distributive spheres); H. Peyton Young, Equity in Theory and Practice 6 (1994) ("Society makes no effort to coordinate distributive decisions across different domains, nor would it make sense to try."). 
by sphere. I say severally, for the sake of the institutional integrity of each sphere. But simultaneously, because the opportunityegalitarian ideal is best realized in each when well realized in all. ${ }^{201}$ But this is, alas, not the place either to commit to or argue for these provisional judgments. More is required to think through the question effectively than space permits here.

My claim here is more modest. It is simply that, where domestic or international rules, programs, or policies are crafted, the crafting ought to be done with equal regard for persons conceived as boundedly responsible agents. That is the first, fundamental right that every person on the globe should be regarded as bearing. It is the secular legal analogue to that "sacredness" that most of us regard as inherent in each of us.

Because it calls for treating one another as equal rightsendowed, boundedly responsible agents, my argument requires that judges, legislatures, executives, administrative agencies, and institutions view their roles slightly differently than they do at present. They are to equalize (a) such benefits and burdens as they are themselves institutionally authorized to bestow and (b) such benefits and burdens as are ethically exogenous in the holding by the persons in regard to whom they are acting. At the same time, they are to dispense in proportion to differential responsibility such ethically endogenous benefits and burdens as they are institutionally authorized to effectively bestow. One entailment of this latter claim, in light of the foregoing subsections, is that legal doctrine and legislative policy ought generally to be elaborated with a view to broadening the reach and improving the operation of the distribution mechanism I have schematized.

These observations bear some possible implications for a thus far inconclusive discussion on institutional roles taking place in the legal-economic literature. One strand of this discussion has it that courts are better suited to maximizing aggregate wealth in the incremental crafting of legal doctrine, while distributional concerns are more efficiently handled through tax policy. ${ }^{202}$ While I must defer

201. For the reasons behind this assertion, see Part III.A.3 in connection with the non-independence of domains.

202. For recent discussion of this long-contested claim, see, e.g., Chris W. Sanchirico, Taxes versus Legal Rules as Instruments for Equity: A More Equitable View, 29 J. Leg. Stud. 797, 820 (2000) (challenging the traditional notion that legal rules cannot address distributional concerns by showing that both tax policy 
more complete discussion of such matters to another venue, two comments can be offered preliminarily.

First, in light of what has emerged over the previous pages, the "efficiency" appealed to in these debates simply will not be of normative interest if decoupled from the responsible agency, equal material opportunity ideal. Second, assigning distributional tasks to certain policy arenas, while designating maximizing tasks to another, raises considerable and possibly inescapable risks. One is that the normatively intelligible maximandum itself cannot be identified apart from the equal material opportunity backdrop against which maximizing activity by a responsible agent takes place. Another is that the institutional decoupling of welfare or income reward from discrete transactional settings tends to undermine the continued practice of responsible agency itself.

A practical corollary to the above discussion involves incentivizing responsible agency. Indeed, rewards to responsible agents should follow as proximately to particular exercises of such responsibility as possible. The want of precisely this form of proximity is one of the flaws that we found to undermine the veiledchoice distribution scenarios, such as Rawls's, addressed supra. In contrast, the opportunity-egalitarian framework ties minute-byminute distributive changes as closely as possible to the voluntary transactions that immediately produce them.

\section{CONCLUSION}

We have covered much ground here. Notwithstanding our progress, it is clear that much more has to be done. Indeed, if I am right, there is more to be done than we have yet realized. For it seems that where the normative theory of law's links to economics is concerned, we have been on the wrong track now for years. We have been fixated upon end-states that are not only ultimately unmeasurable, but are also normatively uninteresting even as objectives. All the while we should have been looking toward

and legal rules can serve distributional purposes in different ways); Louis Kaplow \& Steven Shavell, Should Legal Rules Favor the Poor? Clarifying the Role of Legal Rules and the Income Tax in Redistributing Income, 29 J. Leg. Stud. 821, 835 (2000) (arguing that Sanchirico's thesis is misleading and does not require modifying their earlier conclusion that legal rules are ill-suited for distributional purposes). 
ethically salient opportunity "inputs" whose right distribution allows rightful "outputs" to take care of themselves.

If collective action affects distributions of benefits and burdens to our fellow persons, we cannot help but think through the ethics of distribution: and if we find, on analysis, that distributive ethics call out for the growing and spreading of material opportunity, we must think through how that can be done.

Consider the breathtaking sweep of the research agenda that opens. What are the actual determinants of real, equal-opportunitygrounded well-being? What means can we develop for more accurately defining the boundary between ethically exogenous and ethically endogenous opportunities? How might we best design means of spreading the former, so that the latter-the sole ethically intelligible maximand-might be maximized? What institutions are better suited for accomplishing this design, and how much functional specialization of such institutions is possible? These questions and others press upon us urgently the moment we see that we can no longer dodge them.

For far too long now-just over a century, in fact-Paretian complacency and its bedfellow, Kaldor-Hicksian wealth fetishism, have worked as a mere ball and chain. They have conferred vetoes upon beneficiaries of morally arbitrary distributions, and for no normatively cognizable reason whatsoever. Now that we see they are not only unnecessary, but in fact incompatible with prescription itself, it is high time we tossed them.

Think of how liberating that will be. It will be freeing of us and our fellows in our roles as human persons inhabiting an ever more integrated globe, whose lives and life prospects together will vastly improve as a result. It will be freeing of scholarship too- of work that can now be both practically useful and theoretically sound. Think also of what this will mean both for law and economics. Both will be reconciled again to their origins, in ethics. Both will again be 
what once they were admitted to be-moral sciences. ${ }^{203}$ Both will be healthy again. For they will be home.

203. Ethics and economics were of course once united under the Cambridge "Moral Sciences Tripos." See, e.g., Robert Skidelsky, John Maynard Keynes 28-29 (1983) (discussing the moral philosophical roots of law and social sciences). And of course Adam Smith, seemingly the patron saint of Chicago, lectured and wrote not only on political economy, but upon ethics and jurisprudence as well. See, e.g., Adam Smith, Lectures on Justice, Police, Revenue and Arms (Edwin Cannan, ed., 1896) (exploring the evolution of principles of governance, public jurisprudence and the laws of nations as well as outlining the principles of domestic and private law); Adam Smith, Lectures on Jurisprudence (R. L. Meek et al. eds., 1978) (evaluating the foundation of systems of government in different countries and presenting his theory of rules by which civil government ought to be directed); Adam Smith, The Theory of Moral Sentiments (Knud Haakonssen, ed., 2002) (exploring the human ability to form moral judgments and proposing a theory of sympathy). 